\title{
Fork Experiments in the Hot Cell Using Spent Fuel Rods for International Nuclear Safeguards
}

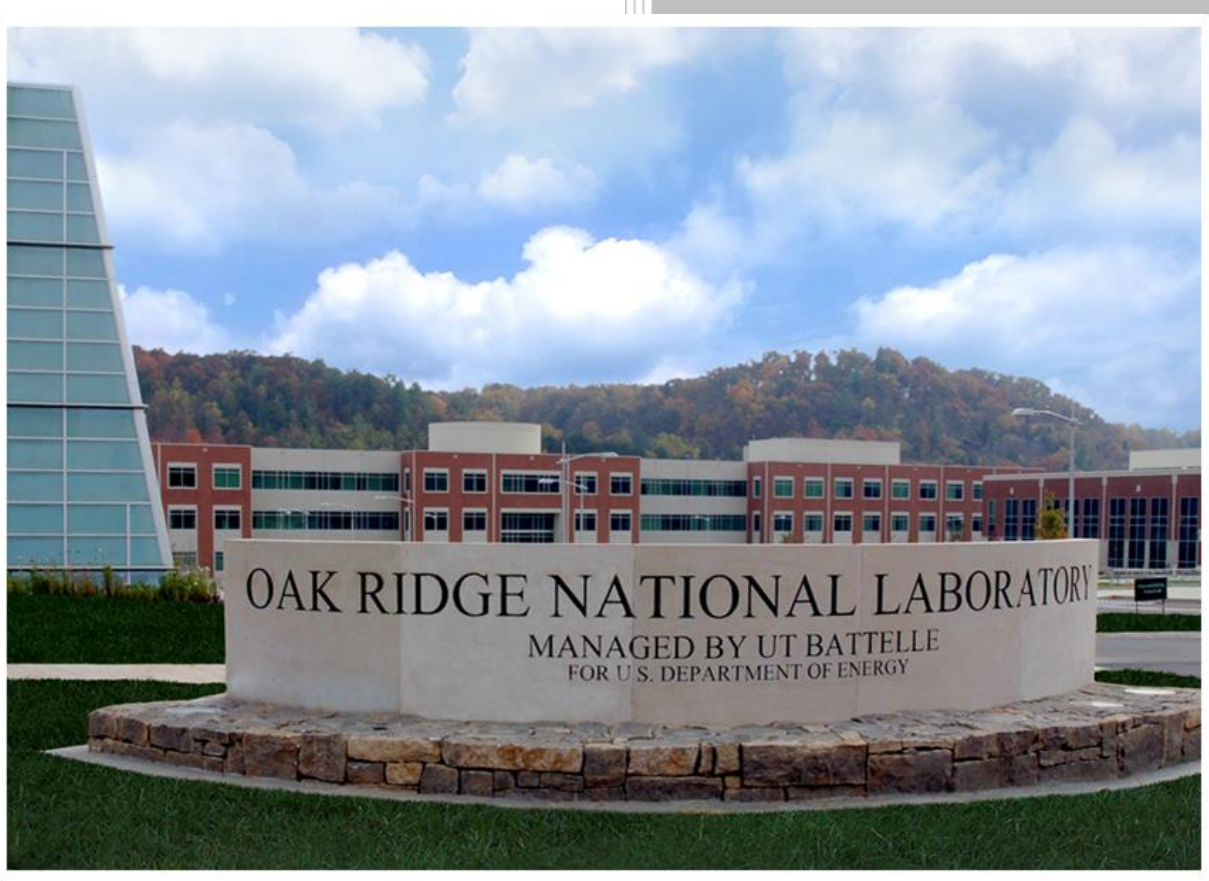

Jianwei $\mathrm{Hu}$

Robert McElroy Andrew Nicholson Stephen Croft

August 2021 


\title{
DOCUMENT AVAILABILITY
}

Reports produced after January 1, 1996, are generally available free via US Department of Energy (DOE) SciTech Connect.

Website www.osti.gov

Reports produced before January 1,1996, may be purchased by members of the public from the following source:

\author{
National Technical Information Service \\ 5285 Port Royal Road \\ Springfield, VA 22161 \\ Telephone 703-605-6000 (1-800-553-6847) \\ TDD 703-487-4639 \\ Fax 703-605-6900 \\ E-mail info@ntis.gov \\ Website http://classic.ntis.gov/
}

Reports are available to DOE employees, DOE contractors, Energy Technology Data Exchange representatives, and International Nuclear Information System representatives from the following source:

Office of Scientific and Technical Information

PO Box 62

Oak Ridge, TN 37831

Telephone 865-576-8401

Fax 865-576-5728

E-mail reports@osti.gov

Website http://www.osti.gov/contact.html

This report was prepared as an account of work sponsored by an agency of the United States Government. Neither the United States Government nor any agency thereof, nor any of their employees, makes any warranty, express or implied, or assumes any legal liability or responsibility for the accuracy, completeness, or usefulness of any information, apparatus, product, or process disclosed, or represents that its use would not infringe privately owned rights. Reference herein to any specific commercial product, process, or service by trade name, trademark, manufacturer, or otherwise, does not necessarily constitute or imply its endorsement, recommendation, or favoring by the United States Government or any agency thereof. The views and opinions of authors expressed herein do not necessarily state or reflect those of the United States Government or any agency thereof. 
Reactor and Nuclear Systems Division

FORK EXPERIMENTS IN THE HOT CELL USING SPENT FUEL RODS FOR INTERNATIONAL NUCLEAR SAFEGUARDS

\author{
Jianwei $\mathrm{Hu}$ \\ Robert McElroy \\ Andrew Nicholson \\ Stephen Croft
}

Date Published: August 2021

\author{
Prepared by \\ OAK RIDGE NATIONAL LABORATORY \\ Oak Ridge, TN 37831-6283 \\ managed by \\ UT-BATTELLE, LLC \\ for the \\ US DEPARTMENT OF ENERGY \\ under contract DE-AC05-00OR22725
}




\section{CONTENTS}

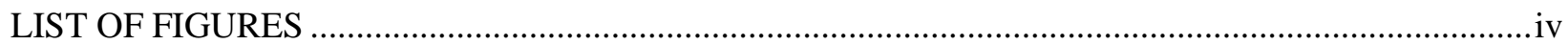

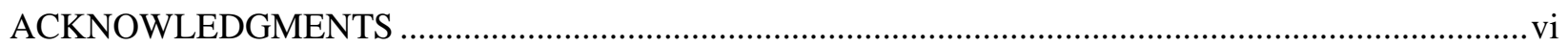

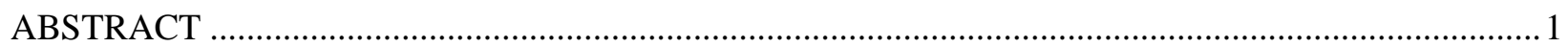

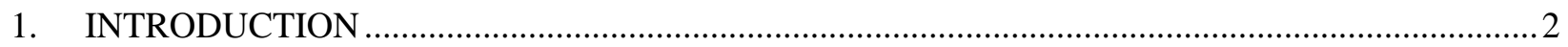

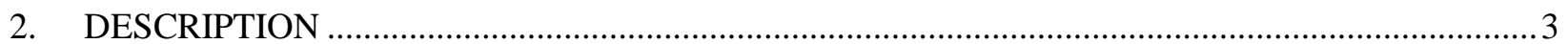

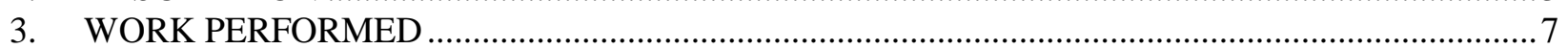

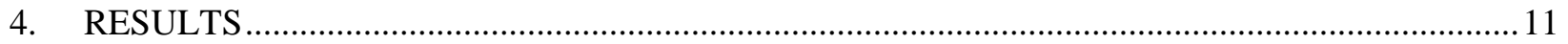

4.1 NEUTRON MEASUREMENT RESULTS FROM THE CALIBRATION FACILITY ..........11

4.2 IC SENSITIVITY TO OPERATING VOLTAGE ................................................................ 16

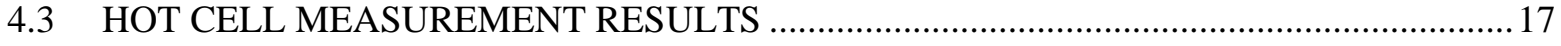

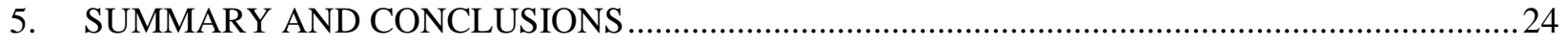

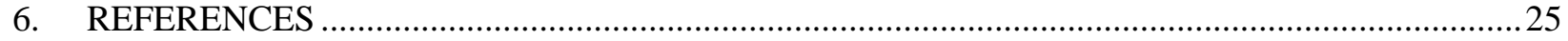




\section{LIST OF FIGURES}

Figure 1. Measurement of a spent fuel assembly in a pool using a Fork detector [2] ............................... 3

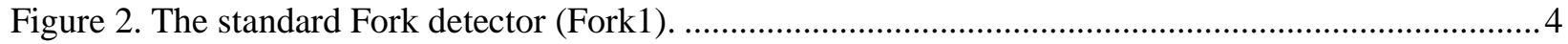

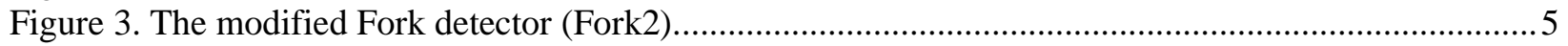

Figure 4. Comparison of detector configurations between Fork1 and Fork2 ..........................................5

Figure 5. (a) The two Amptek 111 preamplifiers in Pb casing in both Fork detectors; (b) the

junction box; (c) one of the Amphenol connectors used in the Fork detector cabling.................... 6

Figure 6. (a) The data acquisition system used to collect neutron and gamma signals from the two

Fork detectors; (b) the ORTEC HV supply............................................................................. 7

Figure 7. Setup for calibrating the Fork detectors at ORNL's RASCAL facility with (left) a ${ }^{252} \mathrm{Cf}$

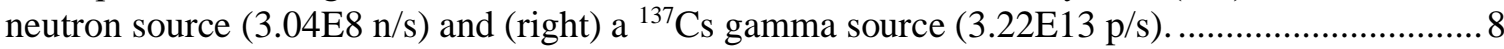

Figure 8. Setup for calibrating the Fork detectors by using a ${ }^{252} \mathrm{Cf}$ neutron source $(3.04 \mathrm{E} 8 \mathrm{n} / \mathrm{s})$ with a polyethylene block for neutron moderation

Figure 9. Setup for measuring a full-length spent fuel rod by using a Fork detector at an ORNL hot cell.

Figure 10. (a) The grid structure used to assemble fuel rods into arrays with four Al blocks and one polyethylene block; (b) a piece of the Al block showing pins to interlock adjacent pieces.

Figure 11. Measurement of a $5 \times 5$ array of 25 full-length spent fuel rods by using a Fork detector at the ORNL hot cell with all locations filled with fuel rods (left) and with a partial defect of eight fuel rods (right).

Figure 12. Diagram to illustrate the first and second set of four fuel rods being replaced in the two partial defect tests.

Figure 13. Neutron count rates measured by the bare_U235FC of Fork1 by using the ${ }^{252} \mathrm{Cf}$ source at RASCAL, as shown in Figure 7 (left).

Figure 14. Neutron count rates measured by the bare_U235FC of Fork1 by using the ${ }^{252} \mathrm{Cf}$ source at RASCAL

Figure 15 . Neutron count rates measured by the polyCd_U235FC of Fork1 by using the ${ }^{252} \mathrm{Cf}$ source at RASCAL, as shown in Figure 7 (left).

Figure 16. Neutron count rates measured by polyCd_U235FC of Fork1 by using the ${ }^{252} \mathrm{Cf}$ source at RASCAL

Figure 17. Neutron count rates measured by ${ }^{238} \mathrm{U}$ FC of Fork 2 by using the ${ }^{252} \mathrm{Cf}$ source at RASCAL.

Figure 18. Neutron count rates measured by ${ }^{3} \mathrm{He}$ tubes of Fork 2 by using the ${ }^{252} \mathrm{Cf}$ source at RASCAL.

Figure 19. Normalized neutron count rates measured by four different neutron detectors of Fork1 and Fork2.

Figure 20. Sensitivity to the operating voltage of the LND 52110 and GE ICs at three different dose rates.

Figure 21. Measured LND 52110 IC signal as a function of dose rates with two different voltages applied to the IC.

Figure 22. Normalized gamma signal measured by the GE ICs of Fork2 along the length of a spent fuel rod at the ORNL hot cell by using three different data acquisition systems.

Figure 23. Neutron count rate measured by the ${ }^{3} \mathrm{He}$ tubes in Fork 2 along the length of a spent fuel rod at the ORNL hot cell by using three different data acquisition systems.

Figure 24. Comparison of count rates collected by the HPGe detector [9] and the Fork detector. 
Figure 25. Comparisons between the Fork count rates with the corresponding calculated neutron and gamma source intensities in nine fuel rods.

Figure 26. Comparisons between the Fork count rates with the corresponding calculated neutron and gamma source intensities in nine fuel rods.

Figure 27. The neutron count rates measured by the ${ }^{3} \mathrm{He}$ tubes of Fork 2 as a function of operating voltage under four different gamma dose rates.

Figure 28. The neutron count rates measured by the FCs of Fork1 as a function of operating voltage under a gamma dose rate of $2,843 \mathrm{R} / \mathrm{h}$.

Figure 29. Partial defect test results of Fork1 and Fork2 performed at the ORNL hot cell. 24 


\section{ACKNOWLEDGMENTS}

This work was funded by the Safeguards Technology Development Program (NA-241) under Office of Nonproliferation and Arms Control, National Nuclear Security Administration of the US Department of Energy. The authors acknowledge the assistance of Ian Gauld (Oak Ridge National Laboratory [ORNL]), Greg Nutter (ORNL), Dr. Kiril Ianakiev (Los Alamos National Laboratory [LANL]), Heather Nordquist (LANL), and Dr. Martyn Swinhoe (LANL) in

designing and executing the experiment. The authors also acknowledge the assistance of Bryan Woody, Jerid Metcalf, and others from ORNL's Irradiated Fuel Examination Laboratory hot cell facility and the assistance of Jason Combs, Anthony Riggs, and others from ORNL's Radiation Standard Calibration Facility. 


\begin{abstract}
This work leveraged the rare availability of 25 full-length pressurized water reactor spent fuel rods and 1 irradiated mixed-oxide rod at an Oak Ridge National Laboratory hot cell. This was done to collect measurement data with two Fork detectors to assess the detectors' capability of verifying operator declaration data and detecting partial defects in spent fuel, which are the two primary goals of international safeguards on spent nuclear fuel. The data can also be used to benchmark the ORIGEN module, which has been adopted in the International Atomic Energy Agency's (IAEA's)/European Atomic Energy Community's (Euratom's) Integrated Review and Analysis Program to predict the Fork detector count rates in real time. In this project, the authors first calibrated two Fork detectors - a standard one and a modified one - by using known strong neutron and gamma sources. Then, the authors measured all 26 fuel rods at multiple locations along the length. The fuel rods were then assembled into three arrays - $2 \times 2,3 \times 3$, and $5 \times 5$ - by using specially designed support grids to mimic fuel assemblies and measure the arrays with both detectors. For the $5 \times 5$ array, 4 and 8 fuel rods of the array were replaced in two separate cases with short stainless-steel rods to mimic two partial defect scenarios, and the arrays were measured before and after the replacements. Polyethylene blocks were used in this experiment to mimic water. The results show that the Fork detectors were able to verify operator declarations and detect partial defects in spent fuel, and the authors were the first to demonstrate this through experiments. A discovery was also made that determined the root cause of the nonlinear response to gamma dose in the ion chambers used in IAEA and Euratom's Fork detectors. After the experiments, both detectors were retrieved from the hot cell for future use. The data collected in this project will be used in a parallel International Nuclear Safeguards Engagement Program (INSEP) project to enhance the safeguards in the Finnish spent fuel encapsulation plant, and the data will be useful to other projects in the future given the increased safeguards needs due to spent fuel transfer and disposal activities worldwide.
\end{abstract}




\section{INTRODUCTION}

The Fork detector is one of two primary nondestructive assay instruments that international safeguards authorities - including the International Atomic Energy Agency (IAEA) and European Atomic Energy Community (Euratom) — have used routinely for spent fuel safeguards inspections since the 1990s. The neutron and gamma signals measured by the Fork detectors are used to verify the highly radioactive spent fuel assemblies stored under water in spent fuel pools. The number of neutrons emitted by a spent fuel assembly is proportional to approximately the fourth power of the assembly average burnup, and the gamma emission is highly dependent on the fuel's cooling time. Under a project sponsored by US Department of Energy (DOE) and National Nuclear Security Administration in FY16 and FY17, Oak Ridge National Laboratory (ORNL) procured a standard Fork detector (referred to as Forkl in this report) and codesigned and procured a modified Fork detector (referred to as Fork2 in this report) with alternate neutron detectors (two ${ }^{3} \mathrm{He}$ tubes and two ${ }^{238} \mathrm{U}$ fission chambers [FCs]) and gamma detectors (two General Electric [GE] high-range ionization chambers [ICs]) from ANTECH and GE. The Fork project leveraged the unique access to full-length spent fuel rods in the ORNL Irradiated Fuel Examination Laboratory hot cell and the detailed operator data of the rods provided by the operator, both of which were made available by a project sponsored by the DOE Office of Nuclear Energy (NE) [1]. The focus of the NE project is to collect and develop data for the continued storage and eventual transport of highburnup spent fuel.

A standard Fork detector is equipped with four FCs for measuring neutrons and two ICs for gammas. IAEA and Euratom use the Fork detector to measure spent fuel assemblies to verify: (1) the operator's declarations of the fuel assembly (e.g., burnup, cooling time) and (2) the absence of partial defects (i.e., removal or substitution of fuel rods from a subject fuel assembly). Such verifications are considered particularly important before the fuel assemblies are transferred to difficult-to-access storage, such as dry storage casks and encapsulation canisters of a geological repository. Dry-cask loading activities are increasing globally because some spent fuel storage pools are approaching the design limits. Finland and Sweden plan to open the world's first two spent fuel encapsulation plants and geological repositories in the 2020s. Some safeguards measurements in the Finland encapsulation plant are expected to be performed in air, for example, in case there is a loss of continuity of knowledge, which introduces unique challenges because most spent fuel safeguards measurements have been performed under water.

Testing the efficacy of a Fork detector for partial defect detection would be difficult in any spent fuel facility because it requires the removal of fuel rods from intact fuel assemblies and measurements of the assemblies before and after the rod removal. The NE project provided a unique opportunity to test the Fork detector for both in-air measurements and partial defect detections because the fuel rods are already in an in-air environment and are already loose and can be formed into various configurations with and without partial defects.

ORNL developed a piece of software called the ORIGEN Module for use by the IAEA and Euratom to predict the Fork neutron and gamma count rates in real time. The software was tested for under-water Fork measurement but has not yet been tested for in-air measurement. To validate the software, the individual spent fuel rods provide simpler neutron and gamma source terms in comparison with spent fuel assemblies as a safeguards inspector would normally encounter. The goals of the Fork project are to (1) quantify the Fork detector's performance for in-air measurement, including partial defect detections; (2) collect data to validate the ORIGEN Module for in-air measurement; and (3) quantify performance improvement (if any) by the hardware modifications to a standard Fork detector. 


\section{DESCRIPTION}

Figure 1 depicts a typical measurement of a spent fuel assembly by using a Fork detector in a spent fuel storage pool [2]. As shown, the detector head is attached to a long pole, which is then fastened onto the guard rail of the bridge or near the pool edge. A crane lifts the fuel assembly and moves it into position between the two tines of the detector. However, in this work, the use of the Fork detector in a hot cell environment in which the fuel rods lay horizontally on a desk was explored. Therefore, the detector was modified accordingly to accommodate different measurement configurations. For example, the pole was replaced by an eye bolt installed onto the back plate to allow the detector head to be lifted up with the two tines pointing downward.

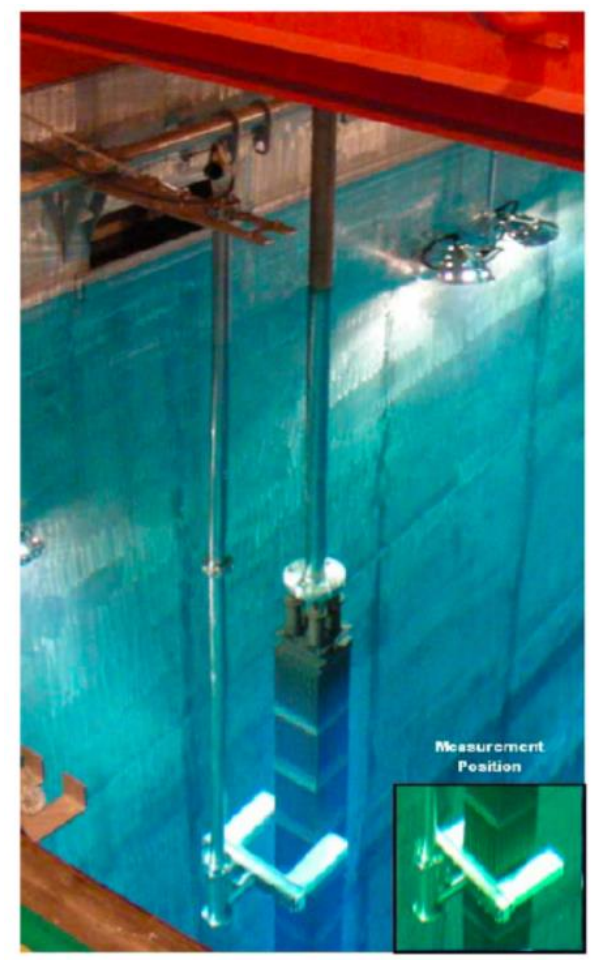

Figure 1. Measurement of a spent fuel assembly in a pool using a Fork detector [2].

Figure 2 shows the standard Fork detector (Fork1) of the Euratom version and its components. There is an insert in each of the two tines that contains two ${ }^{235} \mathrm{U}$ (with $93 \%{ }^{235} \mathrm{U}$ enrichment) FCs and one LND IC. The insert is a polyethylene cylinder with one quadrant voided out, and the outer surface of the insert is covered with a thin layer of $\mathrm{Cd}(0.5 \mathrm{~mm}$ thick) to absorb thermal neutrons. There are two holes in the insert - one for the FC and the other for the IC - and this FC is referred to as polyCd_U235FC. The other FC is installed in the voided quadrant, and this FC is referred to as bare_U235FC. Each FC detects different neutrons. The bare_U235FC detects predominantly thermal neutrons, and the polyCd_U235FC detects mainly fast and epithermal neutrons, even though all four FCs are identical by themselves. The signals of the two bare_U235FCs are combined by the detector electronics into one neutron channel, which is referred to thermal neutron or $n A$ in some of the authors' previous publications [3]. The signals of the two polyCd_U235FCs are combined into a fast neutron channel and referred to as $n B$. In IAEA's version of the standard Fork detector, each tine is a solid cylinder of polyethylene and there are three holes in each cylinder. Two of holes are filled with two identical ${ }^{235} \mathrm{U}$ FCs, and one is filled with an LND IC. The two neutron channels of the IAEA version are the same, detecting neutrons with all energies (i.e., no Cd cover is used). FCs with same model were used in both detector versions. LND-52110 IC is used in 
the Euratom version, and LND-52113 IC is used in the IAEA version, although the specifications of both models are similar [4] [5]. The recent models of both Fork detector versions are provided by ANTECH [6]. The authors' previous experience with the Fork detector was with the Euratom version, which provides an additional neutron signal compared to the IAEA version. This led to the choice of a Euratom version in this work with the advantage that the Euratom version will provide all the signals that the IAEA version would provide. For this reason, the Euratom version of the Fork was selected for this work.

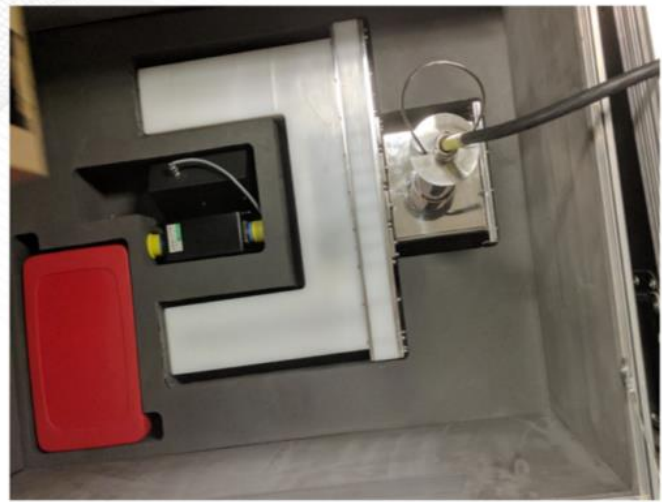

(a)

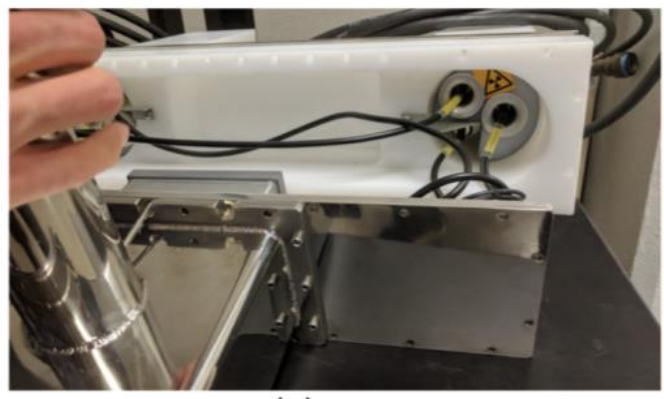

(c)

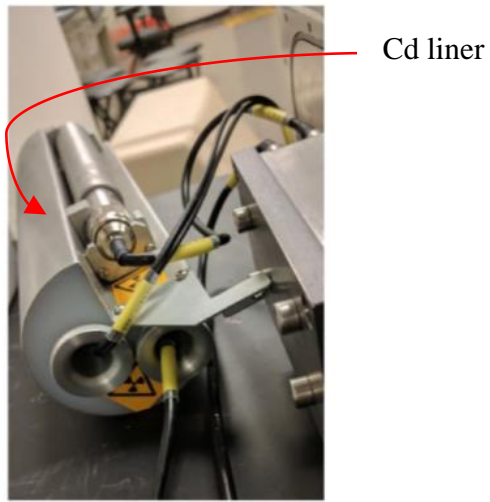

(b)

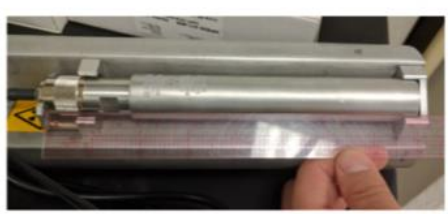

(d)

Figure 2. The standard Fork detector (Fork1). (a) The Fork detector in the container; (b) one of the two inserts containing two ${ }^{235} \mathrm{U}$ FCs and one LND IC; (c) the rear view of the detector with the back panel detached; (d) one of the four identical ${ }^{235} \mathrm{U}$ FCs contained in this detector.

Figure 3 shows the modified Fork detector (Fork2) used in this work and its components. Similar to the IAEA Fork, this detector has three holes directly drilled out in each tine with the larger hole for the $\mathrm{He}^{3}$ tube $\left(1.27 \mathrm{~cm}\right.$ in diameter) and its $\mathrm{W}$ shielding $\left(1.1 \mathrm{~cm}\right.$ thick), one hole for a ${ }^{238} \mathrm{U}$ FC (with $\sim 99.8 \%{ }^{238} \mathrm{U}$ enrichment) and the other for a GE IC. The GE IC is rated for a much higher gamma flux range, 1E8 R/h, than that of an LND IC (1E4 R/h). The LND IC was found to have nonlinear response to a gamma dose rate in the authors' previous work [3]. The IAEA previously reported that the ${ }^{235} \mathrm{U}$ FCs used in the standard Fork detectors have caused difficulties in Fork detector transportation and deployment due to the fissile materials that the FCs contain [7]. Fork1 contains $\sim 0.5 \mathrm{~g}$ of ${ }^{235} \mathrm{U}$. Neither ${ }^{3} \mathrm{He}$ tubes nor ${ }^{238} \mathrm{U}$ FCs contain accountable fissile materials. ${ }^{238} \mathrm{U}$ FC is only sensitive to fast neutrons and could be a good choice for hot cell measurement (i.e., an unmoderated environment). The ${ }^{3} \mathrm{He}$ tubes are sensitive to gamma radiations. To reduce the influence of gamma radiations on the neutron counting, a smaller diameter tubes $\left(1.27 \mathrm{~cm}\right.$ outer diameter) and nitrogen quench gas are used in these two ${ }^{3} \mathrm{He}$ tubes with $3 \mathrm{~atm}$ gas pressure. Additionally, two annular $\mathrm{W}$ tubes are used to reduce the gamma dose on the ${ }^{3} \mathrm{He}$ tubes. The outer diameters of the tungsten tubes are limited to $3.5 \mathrm{~cm}$ in this work to fit in the existing polyethylene tines and to have some polyethylene outside the tubes for neutron moderation. 


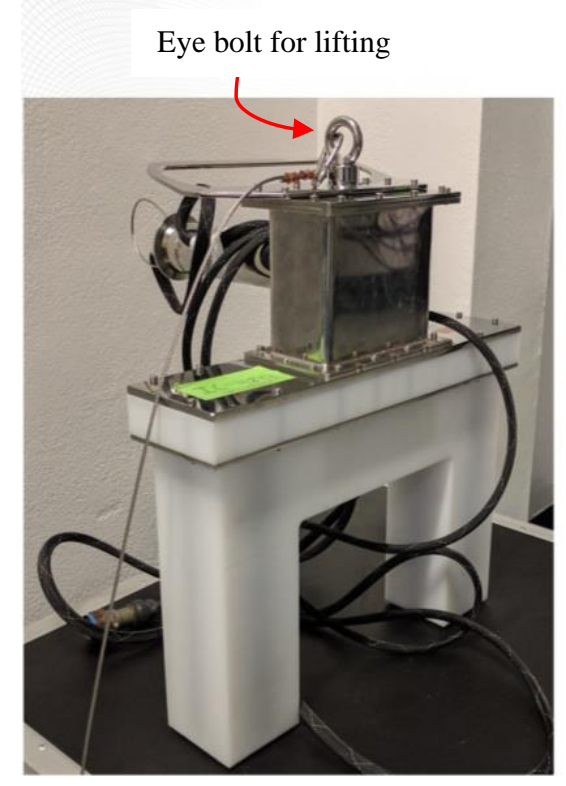

(a)

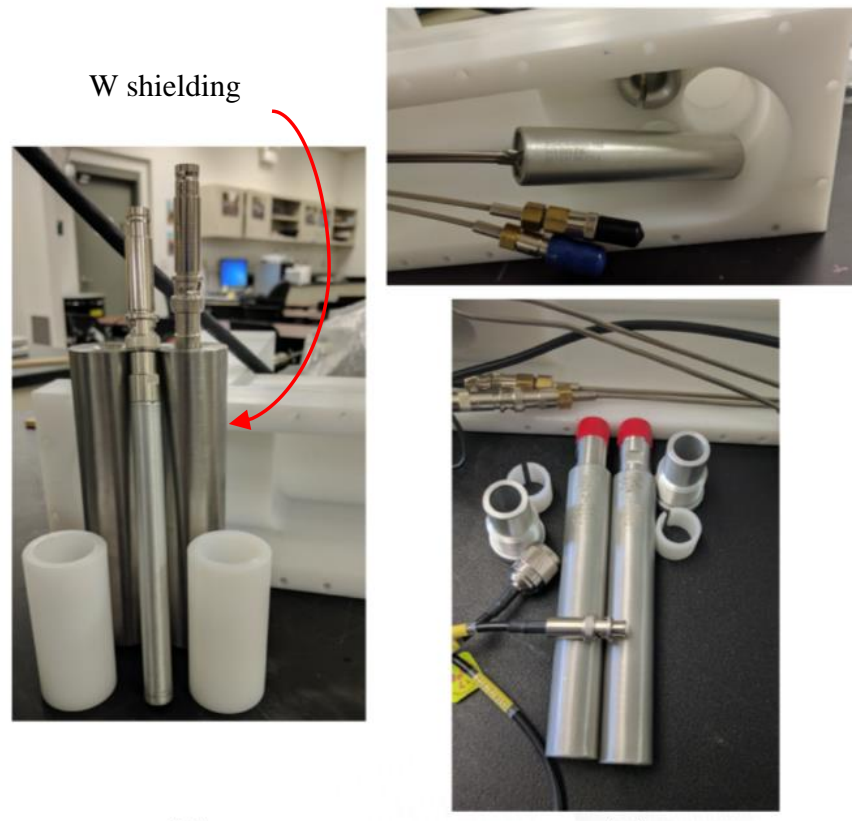

(b)

(c)

Figure 3. The modified Fork detector (Fork2). (a) The Fork detector; the added eye bolt on the top is for lifting in experiment; (b) the two ${ }^{3} \mathrm{He}$ tubes and its W shielding and poly space holder; (c) the GE IC (top) and the ${ }^{238} \mathrm{U}$ FCs (bottom).

Figure 4 compares the detector configurations between Fork1 and Fork2. As shown, the LND IC is replaced by a GE IC in Fork2, and the two ${ }^{235} \mathrm{U}$ FCs are replaced by a ${ }^{3} \mathrm{He}$ tube and a ${ }^{238} \mathrm{U} F \mathrm{~F}$. The ${ }^{3} \mathrm{He}$ tube took the LND ICs position to accommodate the W shielding for the ${ }^{3} \mathrm{He}$ tube.

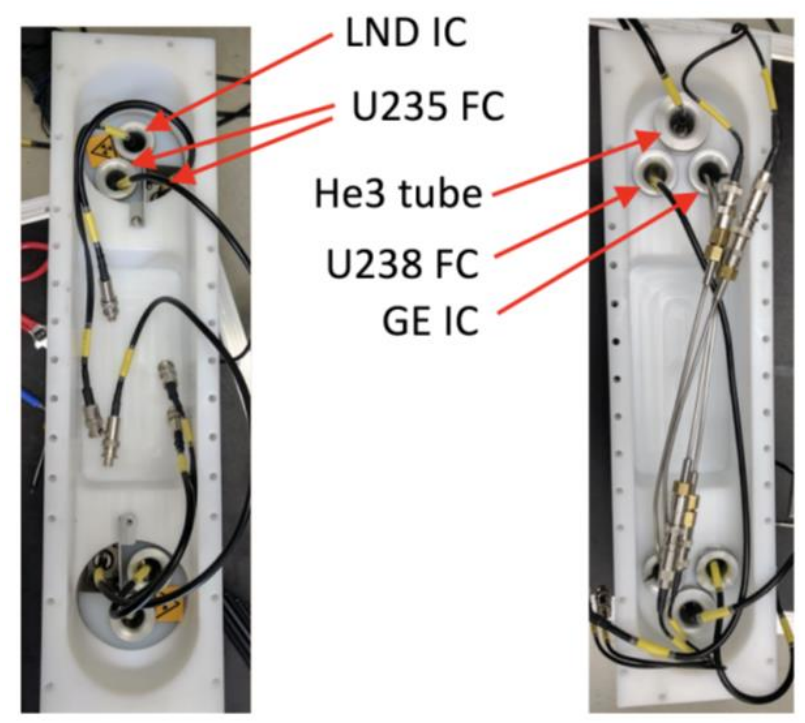

(a) Fork1

(b) Fork2

Figure 4. Comparison of detector configurations between Fork1 and Fork2. 
Figure 5 shows some additional components of the Fork detector system. As shown in Figure 5(b), the IC signals from each side (i.e., tine) are combined here, and four neutron signals are combined into two. The neutron signals are processed by the two Amptek 111 preamplifiers, which are shown in Figure 5(a), with each preamplifier for each neutron channel. Figure 5(c) shows one of the Amphenol connectors and the wires used in the multi-coax cable of Fork1 to collect detector signals and provide high voltages (HVs) to the detectors. The central holes in the wires are used to mate with the pins inside the sockets in the connector. The wire screens must be connected to the screens of the sockets to complete the connection. Such connections must be made by experienced technicians via special crimping tools. A multi-coax cable for Fork1 failed in the lab testing stage of this work, probably due to some weak connections near the connectors. A replacement cable with more rugged designs was made by ANTECH and delivered in time for the experiment. For Fork1, there are six wires used in the multi-coax cable, two wires for the neutron signal, one wire for the IC signal, one wire for the HV for the FCs, one wire for the HV for the IC, and one wire for the $5 \mathrm{~V}$ for the preamplifiers. Fork 2 has one additional wire to provide $\mathrm{HV}$ for the ${ }^{3} \mathrm{He}$ tubes. The HVs applied on ICs are negative, but absolute voltage values are used in this writing for brevity. SMC-2100A and its associated software limits the HV for ICs to less than or equal to $400 \mathrm{~V}$, and MiniGrand and its associated software limits that to $300 \mathrm{~V}$.

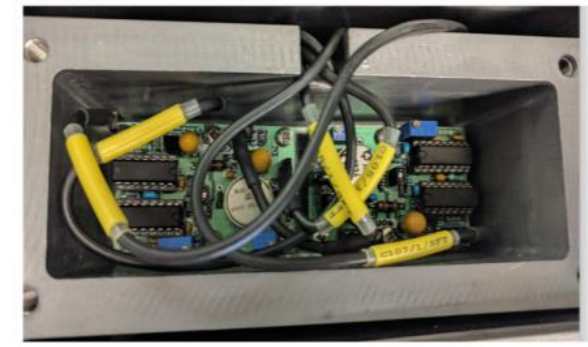

(a)

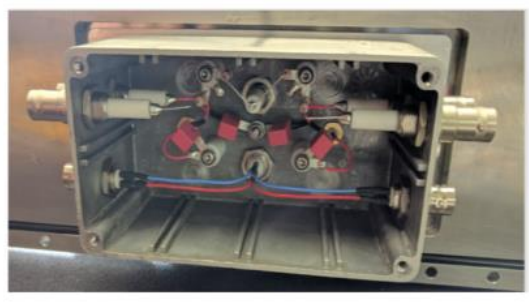

(b)

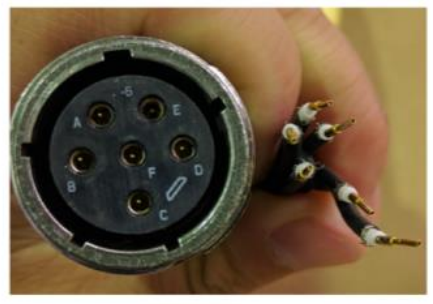

(c)

Figure 5. (a) The two Amptek 111 preamplifiers in Pb casing in both Fork detectors; (b) the junction box; (c) one of the Amphenol connectors used in the Fork detector cabling.

Figure 6(a) shows the data acquisition systems used in this work. Euratom has used SMC-2100A, which was provided by ANTECH, and the Neutron Junction box to operate its Fork detectors, and IAEA has used MiniGrand for its Fork detectors. A MiniGrand was provided to this work by Dr. Kiril Ianakiev from Los Alamos National Laboratory (LANL). A JSR-15 is used to provide HV to the ${ }^{3} \mathrm{He}$ tubes and collect neutron count rates from ${ }^{3} \mathrm{He}$ tubes. Keithley PicoAmmeter is used to directly measure the electric current from the ICs. ANTECH's MasterFDet software is installed on the laptop to run SMC-2100A and LANL's MIC is installed for MiniGrand. Additionally, an ORTEC HV supply is used to provide HV to the ICs, and it was found to be able to supply higher and more stable HV than either SMC2100A or MiniGrand. SMC2100A can only supply up to $400 \mathrm{~V}$ for the IC, and MiniGrand can only supply up to $300 \mathrm{~V}$. One goal of this work was to investigate the cause of nonlinear response in the LND ICs, and the data acquisition system was one of the items that was investigated. 


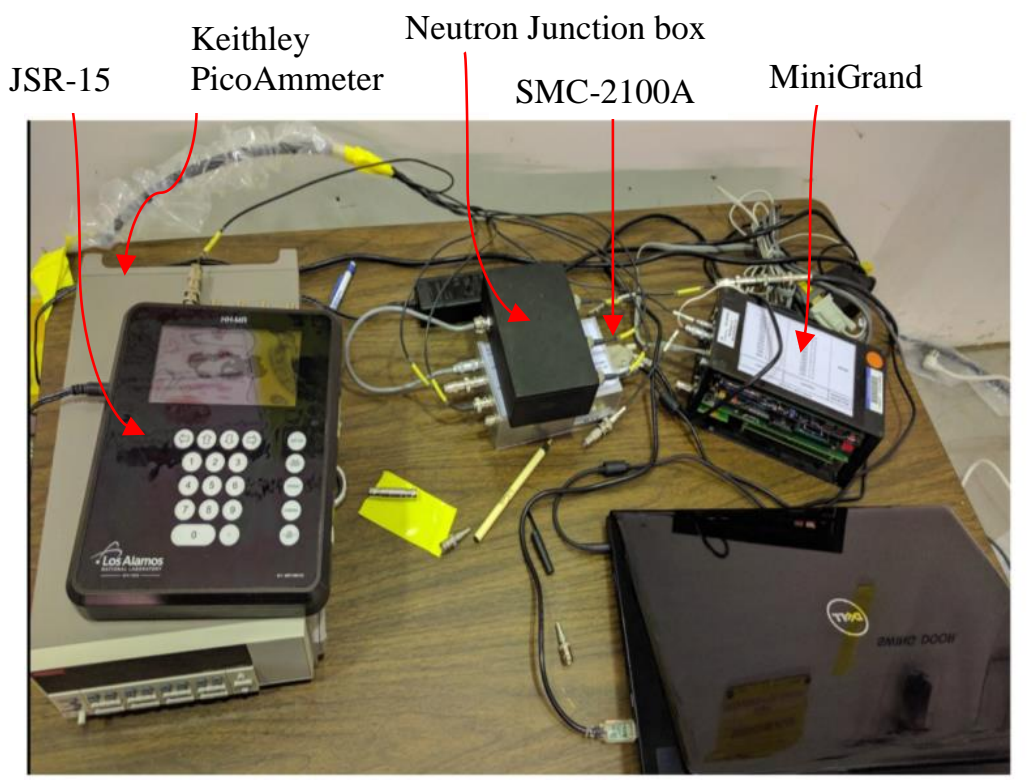

(a)

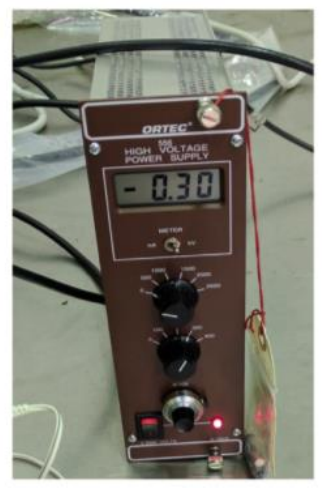

(b)

Figure 6. (a) The data acquisition system used to collect neutron and gamma signals from the two Fork detectors; (b) the ORTEC HV supply.

\section{WORK PERFORMED}

Before the Fork detectors were loaded into the hot cell, they were tested and calibrated in ORNL's Radiation Standards Calibration (RASCAL) facility. Figure 7 (left) shows a calibration measurement of the Fork detector by using a strong ${ }^{252} \mathrm{Cf}$ neutron source at RASCAL, which emits 3.04E8 neutrons per second. The detector was placed at different distances from the neutron source. Similarly, as shown in Figure 7 (right), the detector was placed in front of a strong ${ }^{137} \mathrm{Cs}$ gamma source to calibrate the ICs response of the Fork detector. The movement, along the track, of the platform that holds the Fork detector is controlled remotely, and the platform's distance from the ${ }^{137} \mathrm{Cs}$ source at any given time is provided by the controlling system; rulers are also installed on both tracks for position readings. The ${ }^{137} \mathrm{Cs}$ source is $\sim 1,000 \mathrm{Ci}$, and it emits 3.22E13 photons per second. As shown, the detector was placed to align the tines with the gamma beam. Given that the gamma beam is collimated, unlike the isotropic ${ }^{252} \mathrm{Cf}$ neutron source, such placement allows for more accurate readings of the IC distance from the ${ }^{137} \mathrm{Cs}$ source and better solid angles toward the source. The IC in the tine further away from the ${ }^{137} \mathrm{Cs}$ source was disconnected so that only one IC was tested at a time. This arrangement allows the measured gamma signal to be better correlated to the IC location. The facility calibrated and provided the gamma dose rates as a function of location. These measurements help characterize the Fork detectors and allow for interpretations of the detector's neutron and gamma signals. Figure 8 shows the setup by using the same ${ }^{252} \mathrm{Cf}$ neutron source as used in Figure 7 but with a polyethylene block for moderating the neutrons to test the detector's response to thermal neutrons. 

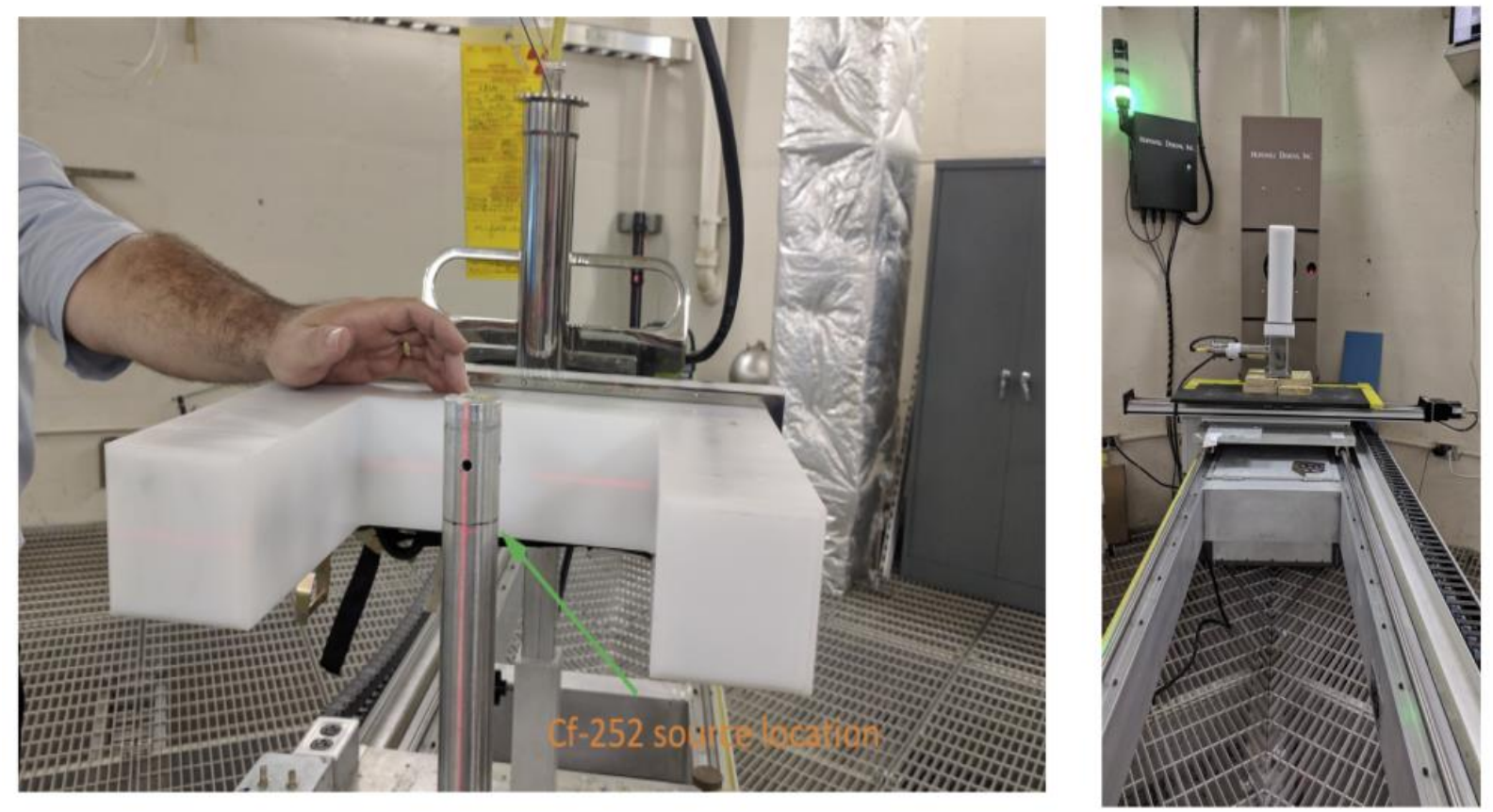

Figure 7. Setup for calibrating the Fork detectors at ORNL's RASCAL facility with (left) a ${ }^{252} \mathrm{Cf}$ neutron source (3.04E8 n/s) and (right) a ${ }^{137} \mathrm{Cs}$ gamma source (3.22E13 p/s).

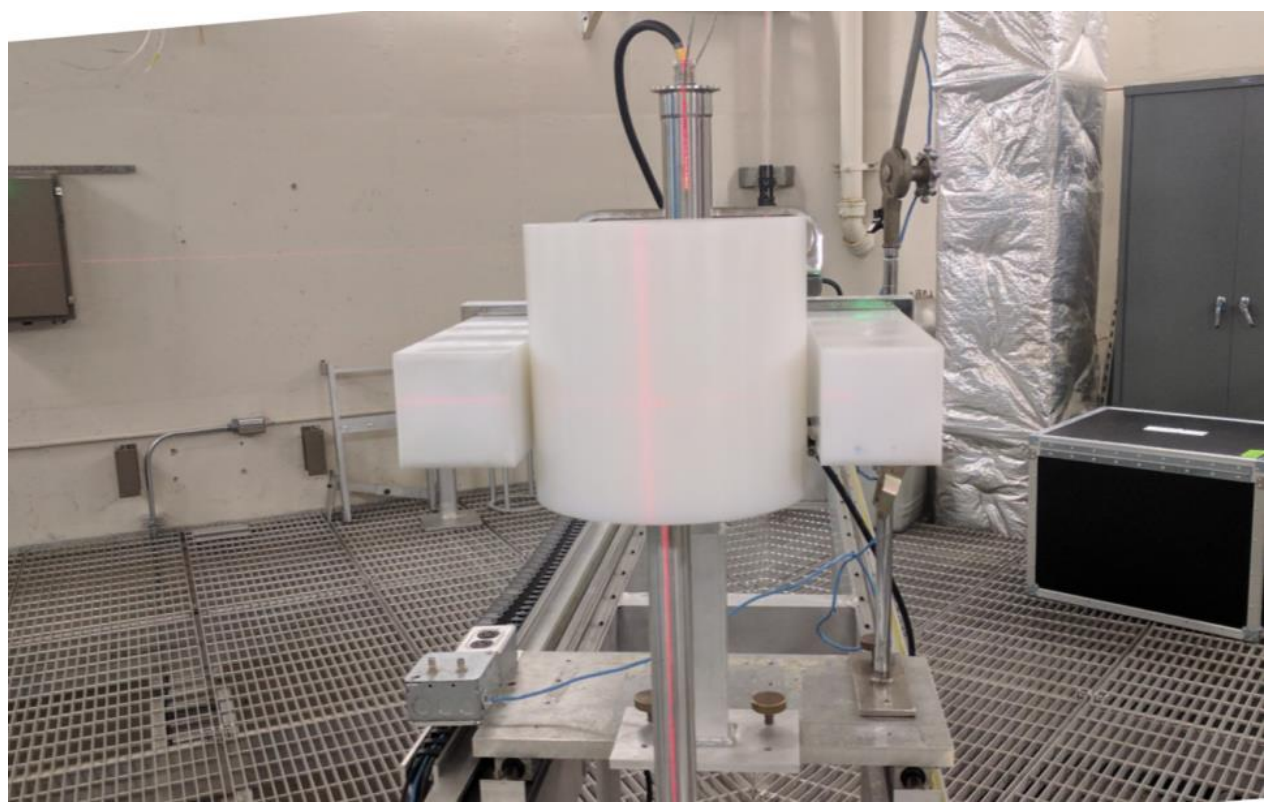

Figure 8. Setup for calibrating the Fork detectors by using a ${ }^{252} \mathrm{Cf}$ neutron source $(3.04 \mathrm{E} 8 \mathrm{n} / \mathrm{s})$ with a polyethylene block for neutron moderation.

After the calibration, the Fork detectors were loaded into a hot cell at ORNL to measure the spent fuel rods. The Fork detectors were first used to measure the individual fuel rods ( $\sim 13 \mathrm{ft}$ long) in a moderated configuration with the white poly block in place and an unmoderated configuration with the poly block removed. Figure 9 shows the measurement of a single fuel rod in the moderated configuration by using ORNL's ADEPT system. To prevent rod bending, a $\sim 15 \mathrm{ft}$ long carrier was used to transfer a fuel rod from the storage cask to the ADEPT. The ADEPT system transfers the rod along the race way (from right 
to left in the figure) to a desired location, allowing the detector to measure a specific section of the rod directly. Rod positioning in the ADEPT system was calibrated for each rod, and the system tracked the rod movement so that the specific location of the rod relative to the Fork detector was always known. For most rods, measurements were taken at 12 axial locations along the length of the rod, which were determined to be sufficient to characterize the variations of the axial burnup profile.

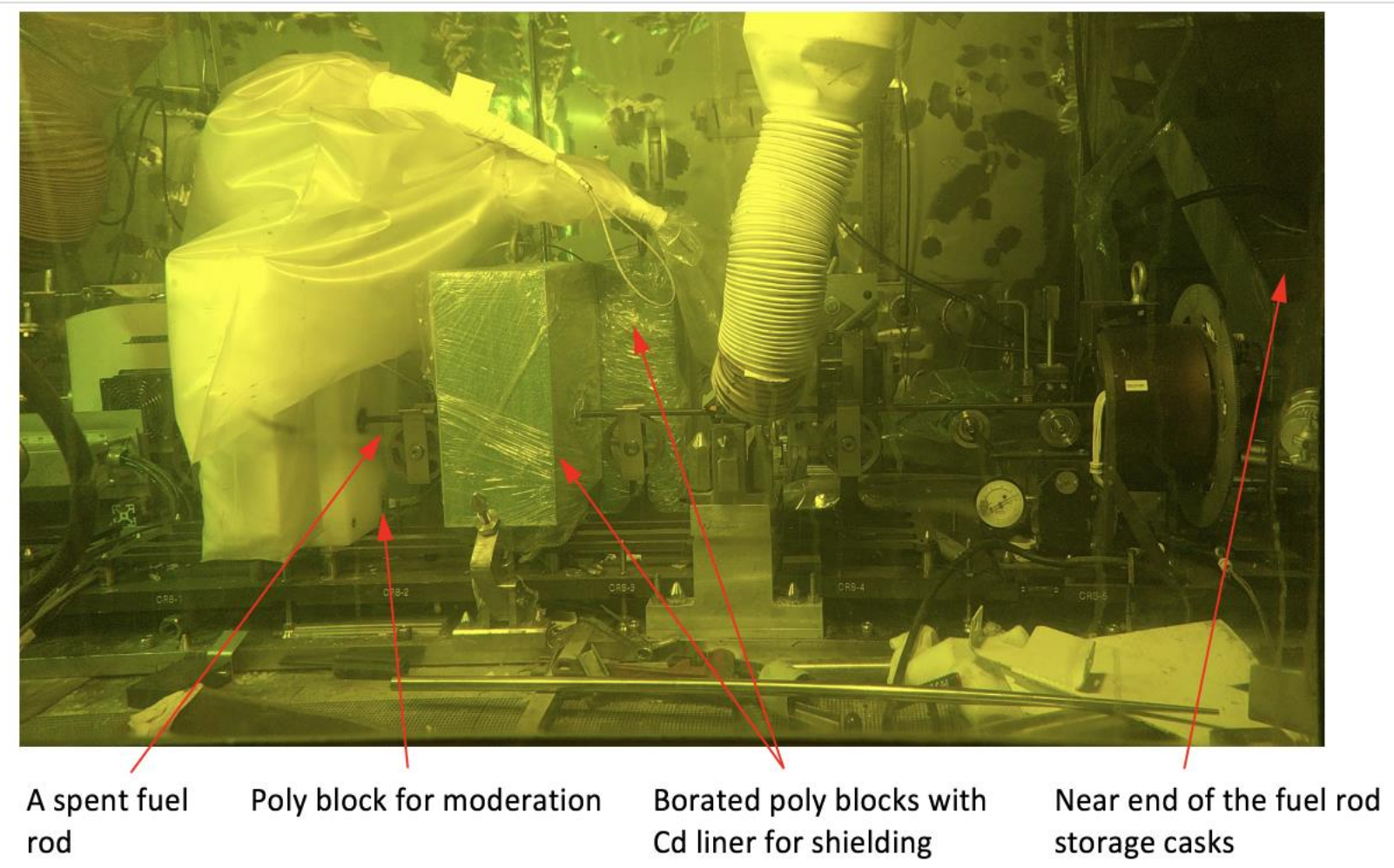

Figure 9. Setup for measuring a full-length spent fuel rod by using a Fork detector at an ORNL hot cell. A poly block (white) was placed around the fuel rod to provide neutron moderation. Two borated poly blocks with $\mathrm{Cd}$ liners were placed on the right-hand side of the detector to block neutrons emitted from the fuel rods stored in the casks. The Fork detector was enclosed in two layers of poly bags to reduce contaminations.

In the second phase, the fuel rods were formed into several different arrays to mimic fuel assemblies, including a $2 \times 2$, a $3 \times 3$, and a $5 \times 5$ array. Figure 10 shows the polyethylene block and the four $\mathrm{Al}$ blocks used to form the individual fuel rods into arrays. These blocks were specially designed and manufactured in this work to support the lengths of assembled rods in their arrays. Each block has five separate pieces with pins and grooves to secure the pieces from above and below; each piece's mating surface has half-cylinder grooves that, when mated, form circular slots for positioning individual rods. "Feet" were also designed at the bottom of the blocks to allow the blocks to be aligned along the fuel's length against the edge of the ADEPT system race way. The array was built from the bottom up with the first row of fuel rods laid on the bottom support piece followed by a second support piece, then a second row of fuel rods, and so on. The rod carrier was elevated to the same level as a given row, and the rod was carefully pulled onto the support structures from the carrier. The blocks and the procedure were designed so that the rods were "nudged" into the desired positions, given that the available space in the hot cell is less than two lengths of the fuel rods and the rod carrier can only be placed at an angle to the blocks. Assembling the arrays was a time-consuming process because great care was taken to avoid damaging the fuel rods. During the process, when more fuel rods were taken out of the storage casks to the array, radiation control technicians measured the radiation levels at various locations outside the hot cell to ensure that the radiation safety limits were not exceeded. 


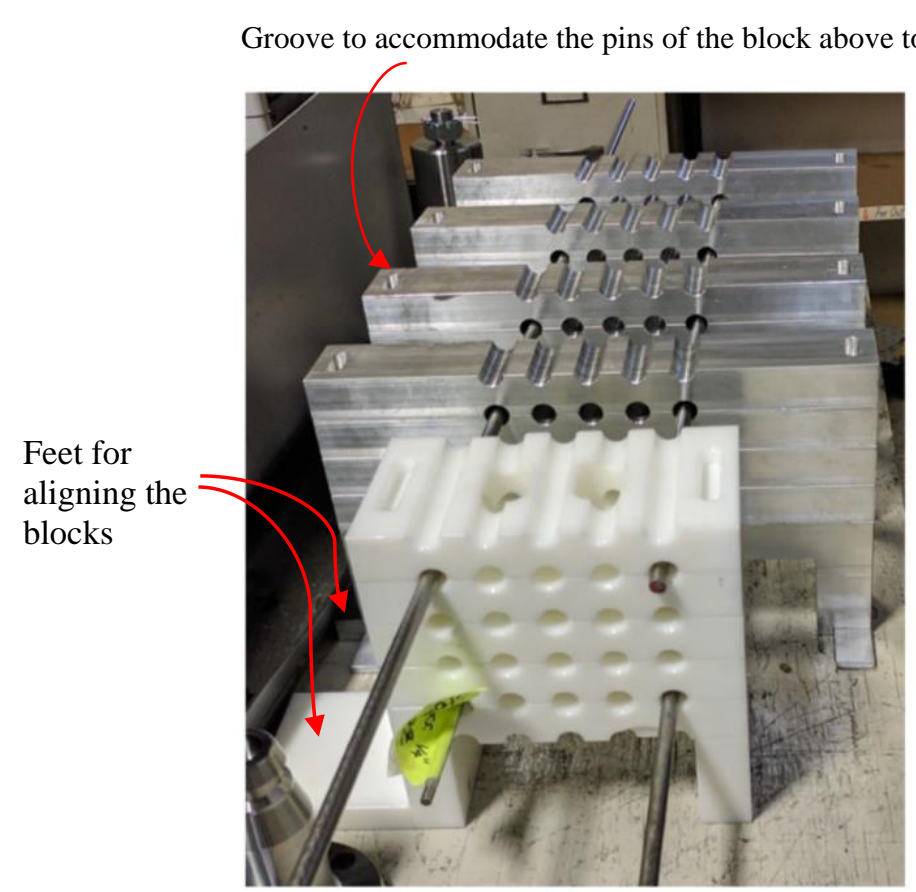

(a)

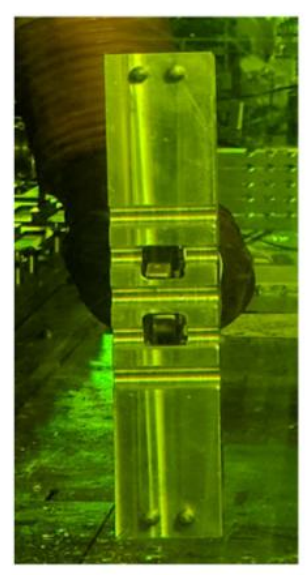

(b)

Figure 10. (a) The grid structure used to assemble fuel rods into arrays with four Al blocks and one polyethylene block; (b) a piece of the Al block showing pins to interlock adjacent pieces.

Figure 11 (left) shows the Fork measurement of the $5 \times 5$ rod array. Eight locations along the array's length were measured with both Fork detectors. Two partial defect scenarios were created and tested with this array, and Figure 11 (right) shows the partial defect of eight fuel rods. The movement of each rod was carefully tracked and recorded to prevent potential rod mix-ups, and individual tagging was also added to each fuel rod when they were used in the arrays, as shown in the figure. To create the first partial defect scenario, four fuel rods were individually pulled out of the $5 \times 5$ array to the rod carrier and then transferred to the storage casks. After, four short ( $4.5 \mathrm{ft}$ instead of $13 \mathrm{ft})$ stainless-steel rods were inserted into the array from the south end of the assembly (i.e., the far end in Figure 11). In a second scenario, an additional set of four fuel rods was pulled out of the $5 \times 5$ array, and four other stainless-steel rods were added. Short stainless-steel rods were used in this work for easier maneuvering in the hot cell by using manipulators that have only two "fingers." The short rods also provided the benefit of allowing Fork detector tests in parts of the array with fuel rods missing and other parts of the array in which fuel rods were substituted with steel rods. Measurements were performed at six locations along the array's length in both scenarios by using both Fork detectors. Figure 12 illustrates the first and second set of four fuel rods being replaced in these two partial defect tests. As shown, the interior rods were replaced in these tests because those partial defects are more challenging to detect. 

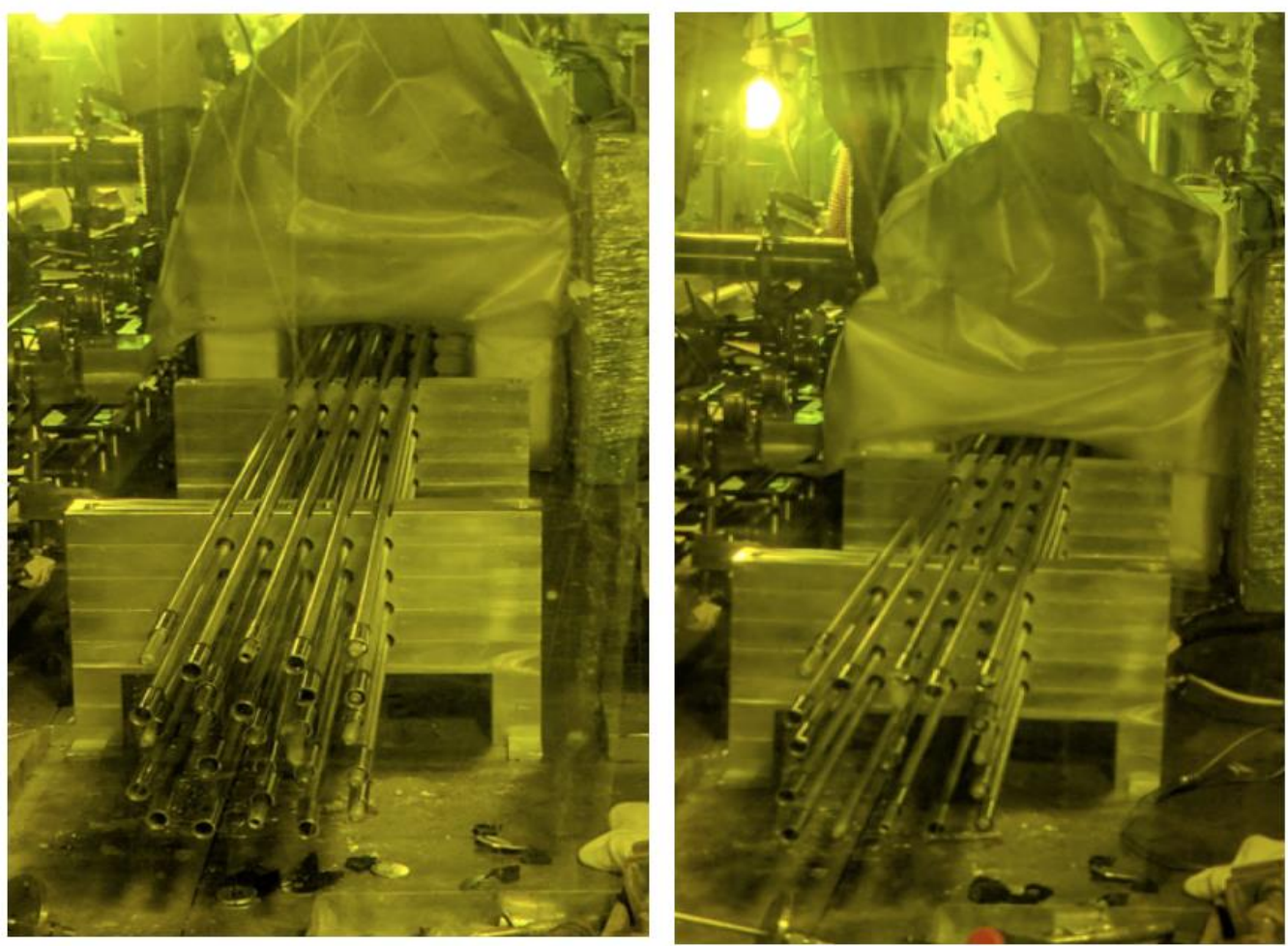

Figure 11. Measurement of a $5 \times 5$ array of 25 full-length spent fuel rods by using a Fork detector at the ORNL hot cell with all locations filled with fuel rods (left) and with a partial defect of eight fuel rods (right). The Fork detector was enclosed in poly bags to reduce contaminations.

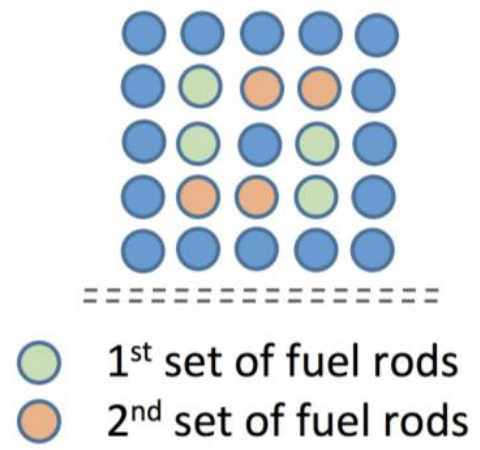

Figure 12. Diagram to illustrate the first and second set of four fuel rods being replaced in the two partial defect tests.

\section{RESULTS}

\subsection{NEUTRON MEASUREMENT RESULTS FROM THE CALIBRATION FACILITY}

Figure 13 shows the neutron count rates measured by the bare_U235FC of Fork 1 by using the ${ }^{252} \mathrm{Cf}$ source at RASCAL. The polyethylene block was not used in these cases, as shown in Figure 7 (left). The count rates were collected by using three different data acquisition systems: SMC-2100A, JSR-15, and MiniGrand. As expected, the neutron count rates decrease as the detector was moved away from the ${ }^{252} \mathrm{Cf}$ source. The neutron count rates collected by the three acquisition systems are in good agreement, although the count rates from SMC-2100A were consistently 2-3\% higher than those from the other two 
systems. The other two differ by less than $0.6 \%$ on most data points except for the last three points that are furthest away from the source. Figure 14 compares the neutron count rates measured by bare_U235FC with and without the use of the polyethylene block, as shown in in Figure 8. The count rates with the block for this detector were approximately three and a half times of that without the block. The polyethene is $\sim 0.5 \mathrm{~cm}$ thick outside the insert, and this FC is located in the void quadrant of the insert; therefore, the neutrons arriving this detector were not sufficiently moderated for detection, given that the average neutron energy for the ${ }^{252} \mathrm{Cf}$ source is $\sim 2.5 \mathrm{MeV}$.

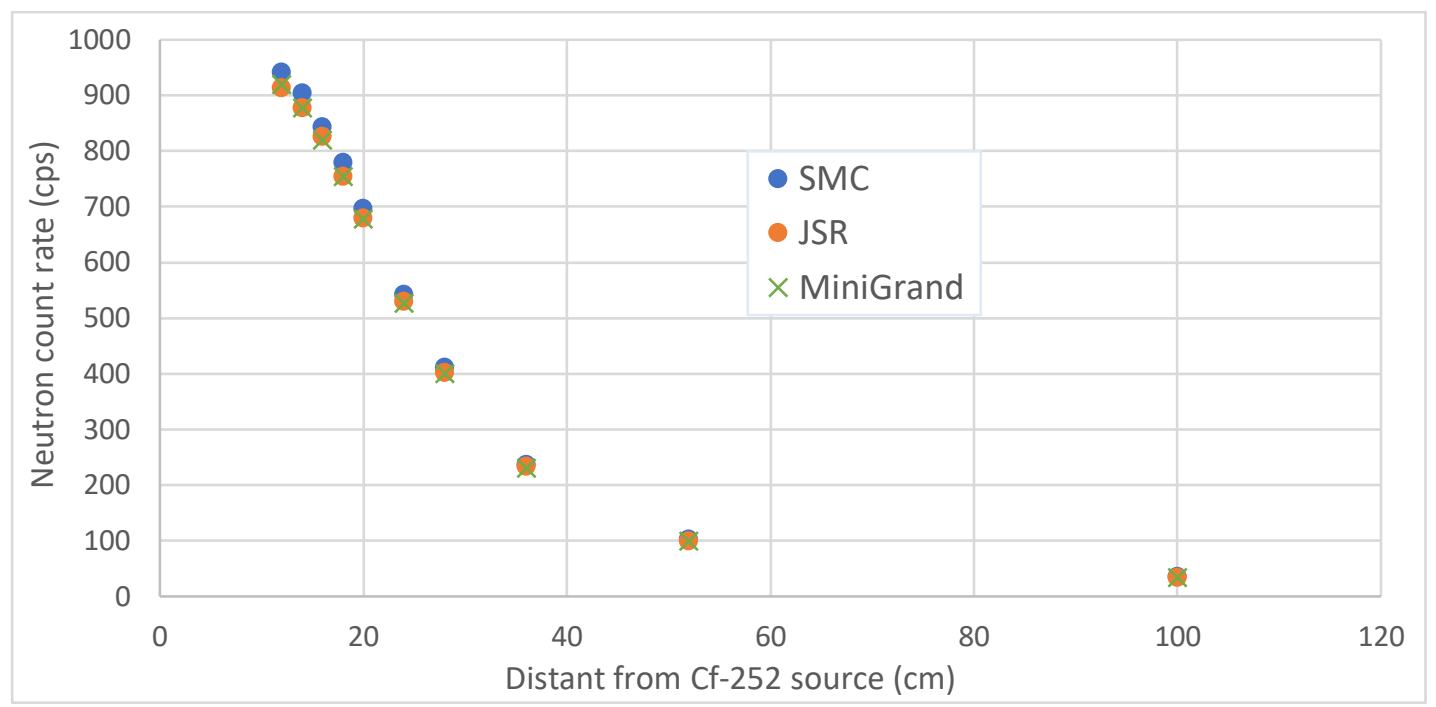

Figure 13. Neutron count rates measured by the bare_U235FC of Fork1 by using the ${ }^{252} \mathrm{Cf}$ source at RASCAL, as shown in Figure 7 (left). The count rates were collected by using three different data acquisition systems.

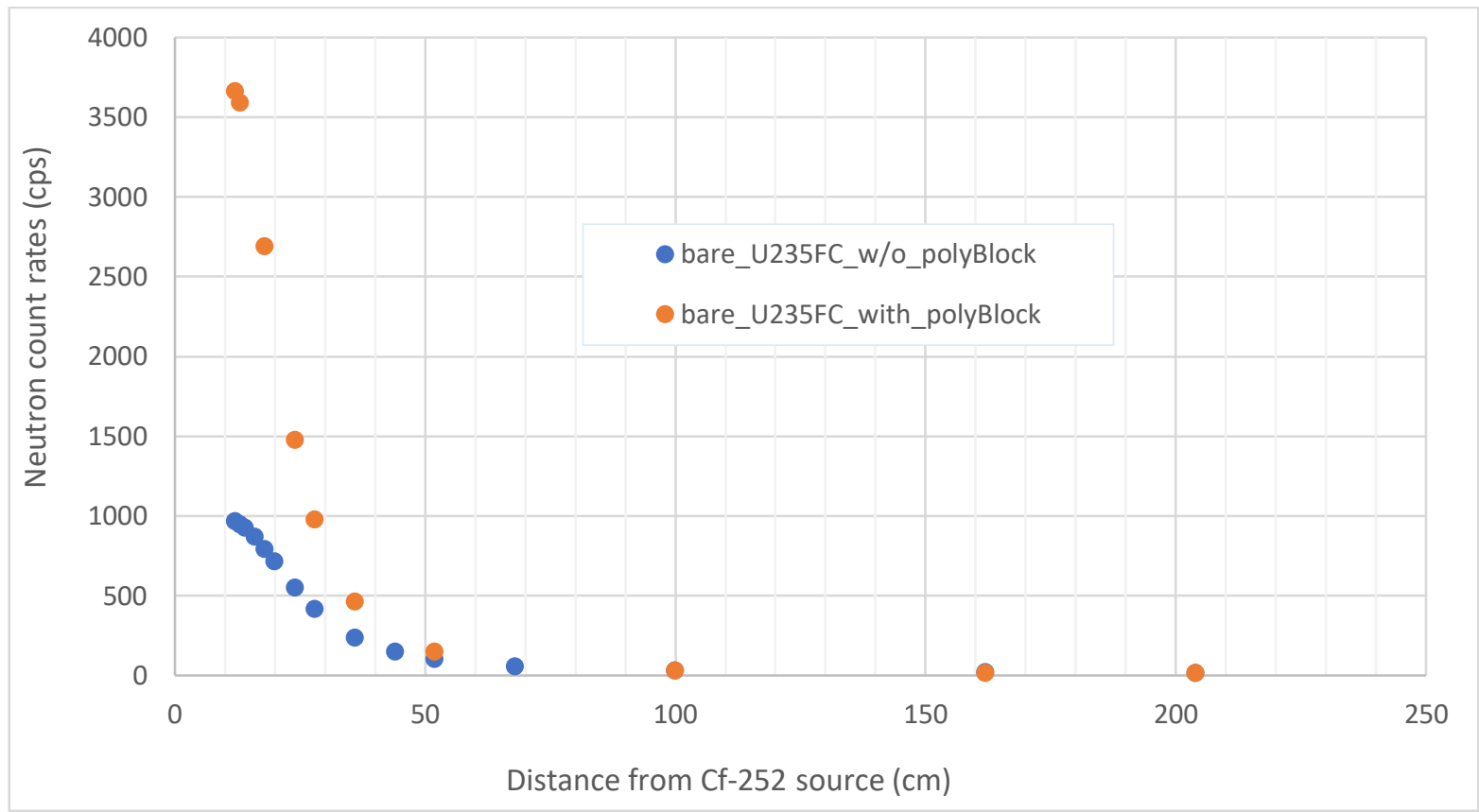

Figure 14. Neutron count rates measured by the bare_U235FC of Fork1 by using the ${ }^{252} \mathrm{Cf}$ source at RASCAL. The polyethylene block (shown in Figure 8) was used in one case and not the other. 
Figure 15 shows the neutron count rates measured by the polyCd_U235FC of Fork 1 by using the ${ }^{252} \mathrm{Cf}$ source at RASCAL, as shown in Figure 7 (left). The count rates were collected by using three different data acquisition systems. A similar trend can be observed as the other FC. The count rates measured by SMC-2100A were about 2-3\% higher than those from the other two systems. The count rates of this FC were approximately five times that of the other FC, even though the FCs are identical in Fork1. This FC is embedded in polyethene in the insert, which provided the additional neutron moderation that a ${ }^{235} \mathrm{U} F C$ needs for detection. The thin layer of $\mathrm{Cd}$ used on this $\mathrm{FC}$ did not appear to significantly reduce the neutron count rates, given that ${ }^{252} \mathrm{Cf}$ emits mostly fast neutrons. Figure 16 compares the neutron count rates of the polyCd_U235FC of Fork1 with and without the use of the polyethene block. The count rates with the block were $\sim 30 \%$ lower than those without the block. The extra moderation provided by the block will increase the fraction of thermal neutrons, leading to high neutron absorption by the Cd cover of this FC. The block itself will also absorb some neutrons.

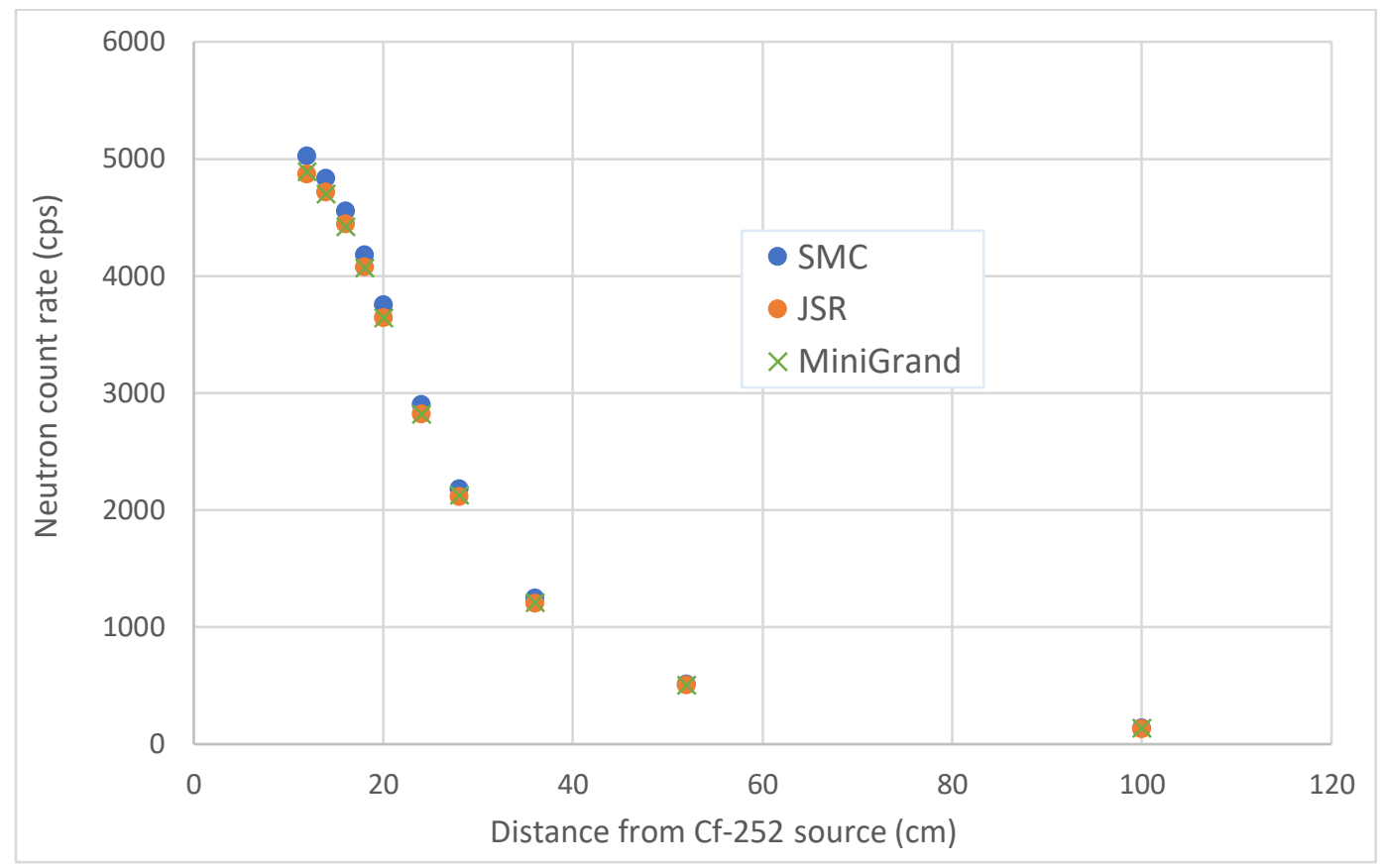

Figure 15. Neutron count rates measured by the polyCd_U235FC of Fork1 by using the ${ }^{252} \mathrm{Cf}$ source at RASCAL, as shown in Figure 7 (left). The count rates were collected by using three different data acquisition systems 


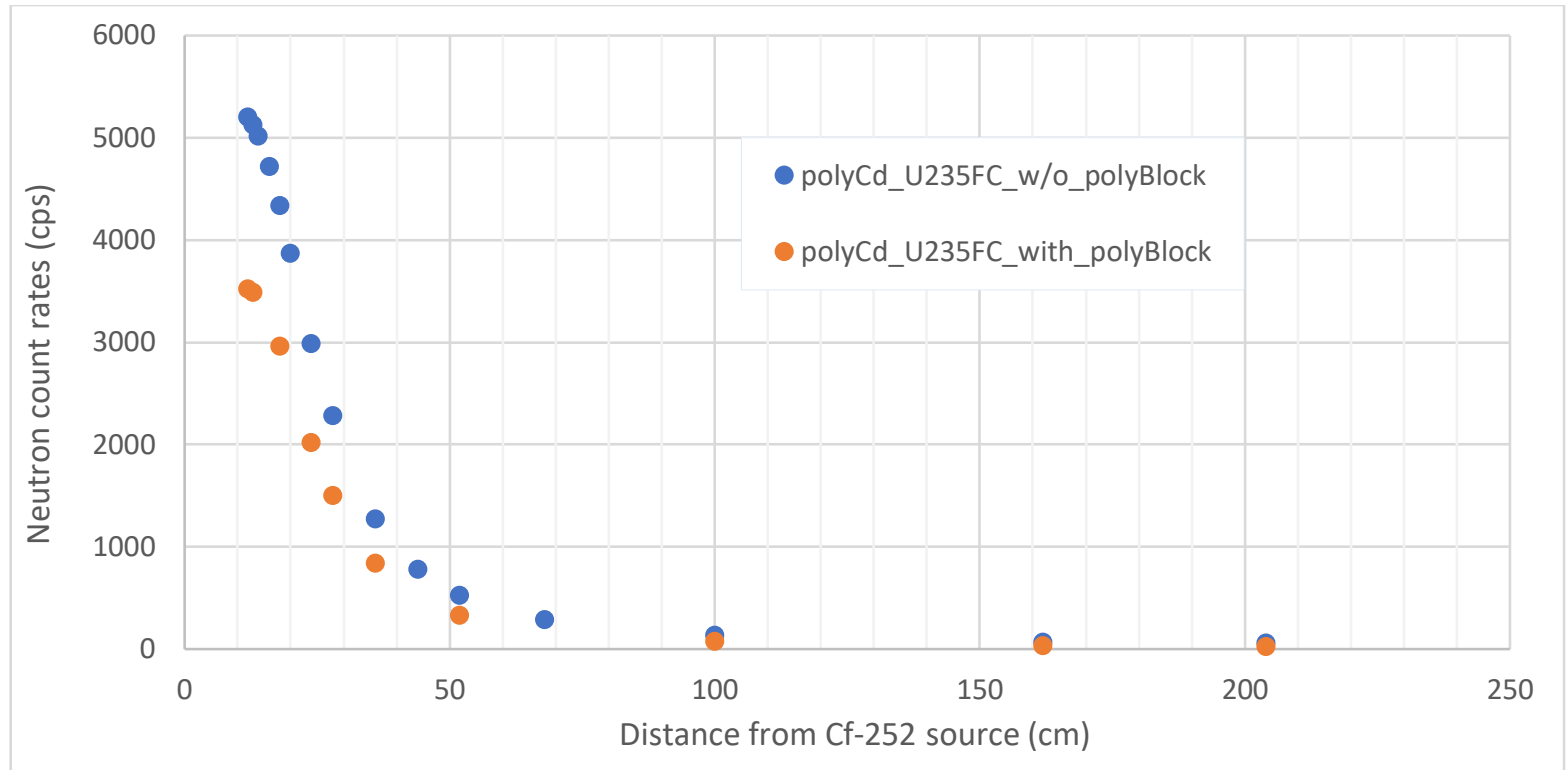

Figure 16. Neutron count rates measured by polyCd_U235FC of Fork1 by using the ${ }^{252} \mathrm{Cf}$ source at RASCAL. The polyethylene block (shown in Figure 8) was used in one case and not the other.

Figure 17 compares the neutron count rates measured by ${ }^{238} \mathrm{U}$ FC of Fork 2 by using the ${ }^{252} \mathrm{Cf}$ source at RASCAL with and without the use of the polyethylene block. The count rates without the block were approximately four times those with the block. Because the ${ }^{238} \mathrm{U} F C$ is predominantly sensitive to fast neutrons, the block reduces the quantity of fast neutrons and leads to lower count rates. The count rates of ${ }^{238} \mathrm{U}$ FC were only $\sim 0.4 \%$ of the polyCd_U235FC.

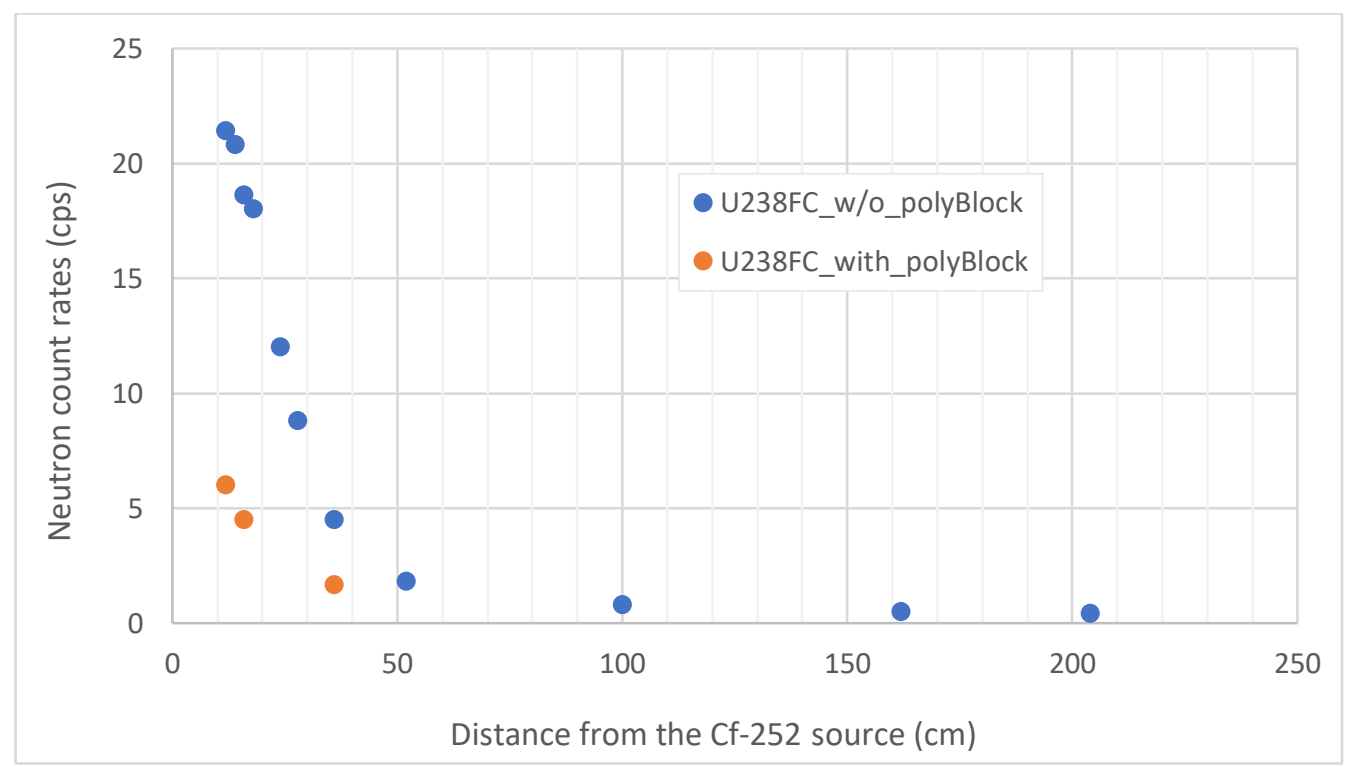

Figure 17. Neutron count rates measured by ${ }^{238} \mathrm{U}$ FC of Fork2 by using the ${ }^{252} \mathrm{Cf}$ source at RASCAL. The polyethylene block (shown in Figure 8) was used in one case and not the other.

Similarly, Figure 18 compares the ${ }^{3} \mathrm{He}$ tubes of Fork2. As shown, using the block reduced the count rates by $\sim 38 \%$, which is similar to the polyCd_U235FC of Fork1. This is understandable because the ${ }^{3} \mathrm{He}$ tubes are embedded in polyethylene in the tines ( $2.8 \mathrm{~cm}$ thick on average), which is probably already sufficient for moderation, and the additional moderation provided by the block increased the neutron 
absorption within the block. Compared with the neutron count rates collected by the ${ }^{235} \mathrm{U}$ FCs shown in Figure 16, the ${ }^{3} \mathrm{He}$ tubes were approximately four times as sensitive as the ${ }^{235} \mathrm{U}$ FCs.

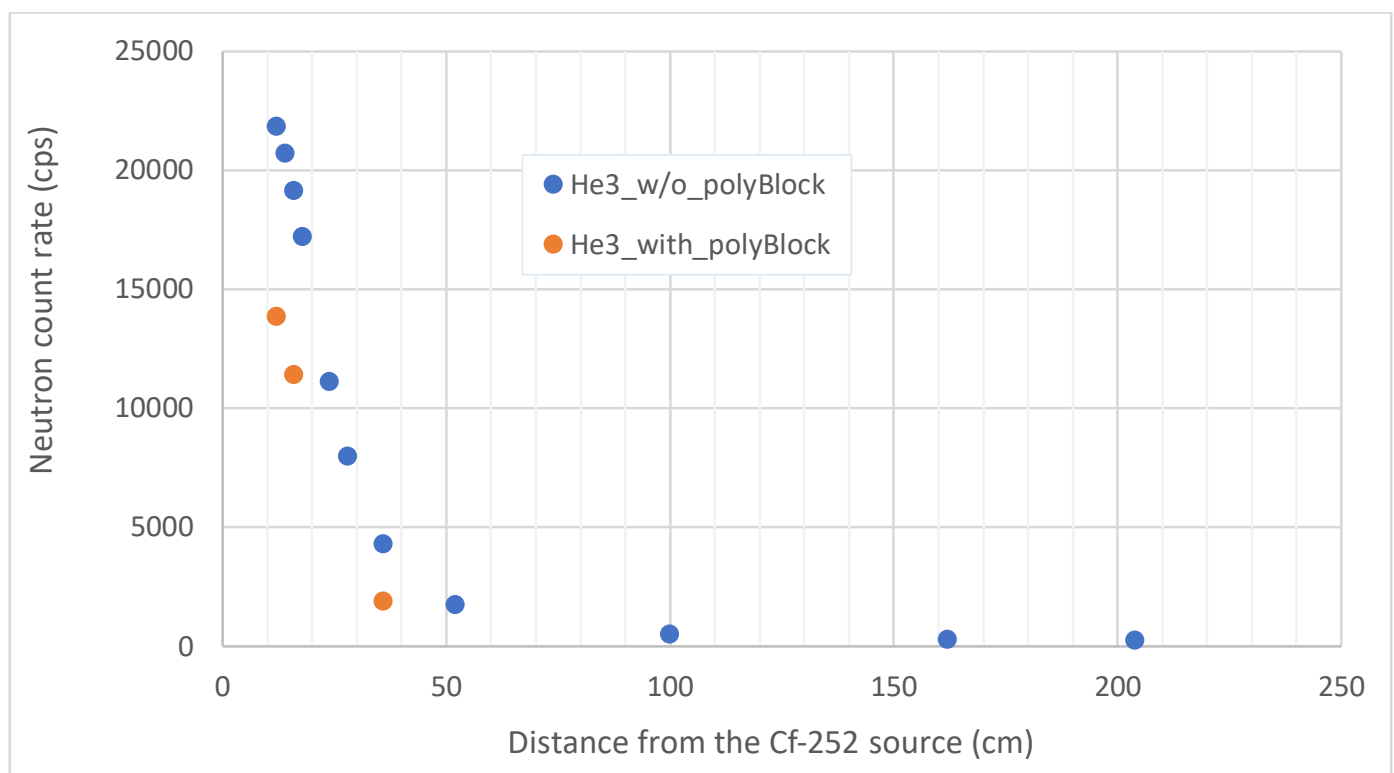

Figure 18. Neutron count rates measured by ${ }^{3} \mathrm{He}$ tubes of Fork 2 by using the ${ }^{252} \mathrm{Cf}$ source at RASCAL. The polyethylene block (shown in Figure 8) was used in one case and not the other.

Figure 19 shows the normalized neutron count rates of Fork1 and Fork2. Each dataset was normalized by its own maxima. The poly block was not used in these cases. Close agreement can be observed from this figure among these datasets, demonstrating that the experiment was conducted correctly and that the neutron detectors performed properly.

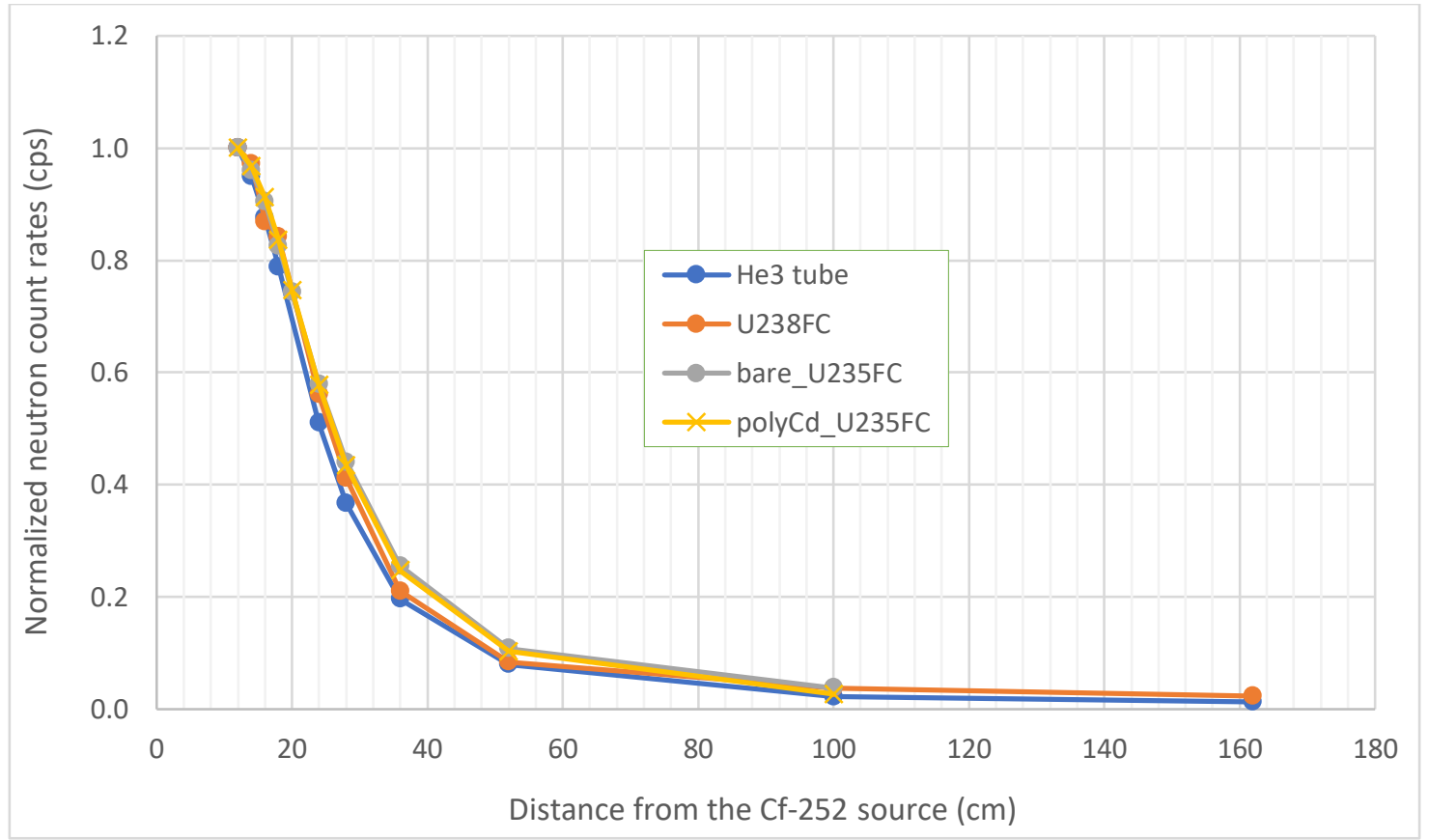

Figure 19. Normalized neutron count rates measured by four different neutron detectors of Fork1 and Fork2. The poly block was not used in these cases. 


\subsection{IC SENSITIVITY TO OPERATING VOLTAGE}

As discussed previously, LND 52110 ICs are used in the Euratom Fork detectors and LND 52113 ICs are used in the IAEA Fork detectors. Both sets of LND ICs have similar characteristics, despite the different model numbers. The ICs in the Euratom Fork detectors were found to have nonlinear response to gamma dose rate in previous work [3], but the root cause was unknown at the time. In this work, the authors used LND 52110 ICs in Fork1 and performed extensive tests with them and with the GE ICs in Fork2.

Figure 20 shows the LND 52110 and GE ICs sensitivity to the operating voltage at three different dose rates. These dose rates were provided by a single fuel rod, the $3 \times 3$ fuel rod array, and the $5 \times 5$ array. As shown, the LND IC is sensitive to the operating voltage, and the sensitivity becomes more severe at higher gamma dose rates. For example, the minimum operating voltage required to return the LND IC to linearity is $200 \mathrm{~V}$ at a dose rate of $489 \mathrm{R} / \mathrm{h}$, and at least $500 \mathrm{~V}$ is needed for $5,471 \mathrm{R} / \mathrm{h}$. The GE IC exhibits much less sensitivity to the voltages. The IAEA and Euratom operate the ICs in their respective Fork detectors at $100 \mathrm{~V}$ [3] [7]. When insufficient voltage is applied, the electric charges created by the gamma radiation recombine before they are collected by the electric field and contribute to the signal output. Figure 21 shows the measured LND IC signals at 100 and $300 \mathrm{~V}$ as a function of gamma dose rates, which were provided by RASCAL. The IC signal was collected by a MiniGrand. At $300 \mathrm{~V}$, the signal was linear with the gamma dose rate. However, at $100 \mathrm{~V}$, the signal was not linear with dose rate, and the detection efficiency deteriorated at higher dose rate, which was consistent with what was previously reported when both the IAEA and Euratom Fork detectors were operated at $100 \mathrm{~V}$ [8] [3]. Higher voltages (>500 V) are likely needed when the Fork detectors are used to measure full spent fuel assemblies because they emit gamma dose rates at tens of thousands roentgen per hour $(\mathrm{R} / \mathrm{h})$, depending on their cooling times [7]. Further study is recommended to determine the minimum voltage needed for full fuel assemblies for the LND ICs used in IAEA and Euratom Fork detectors. 


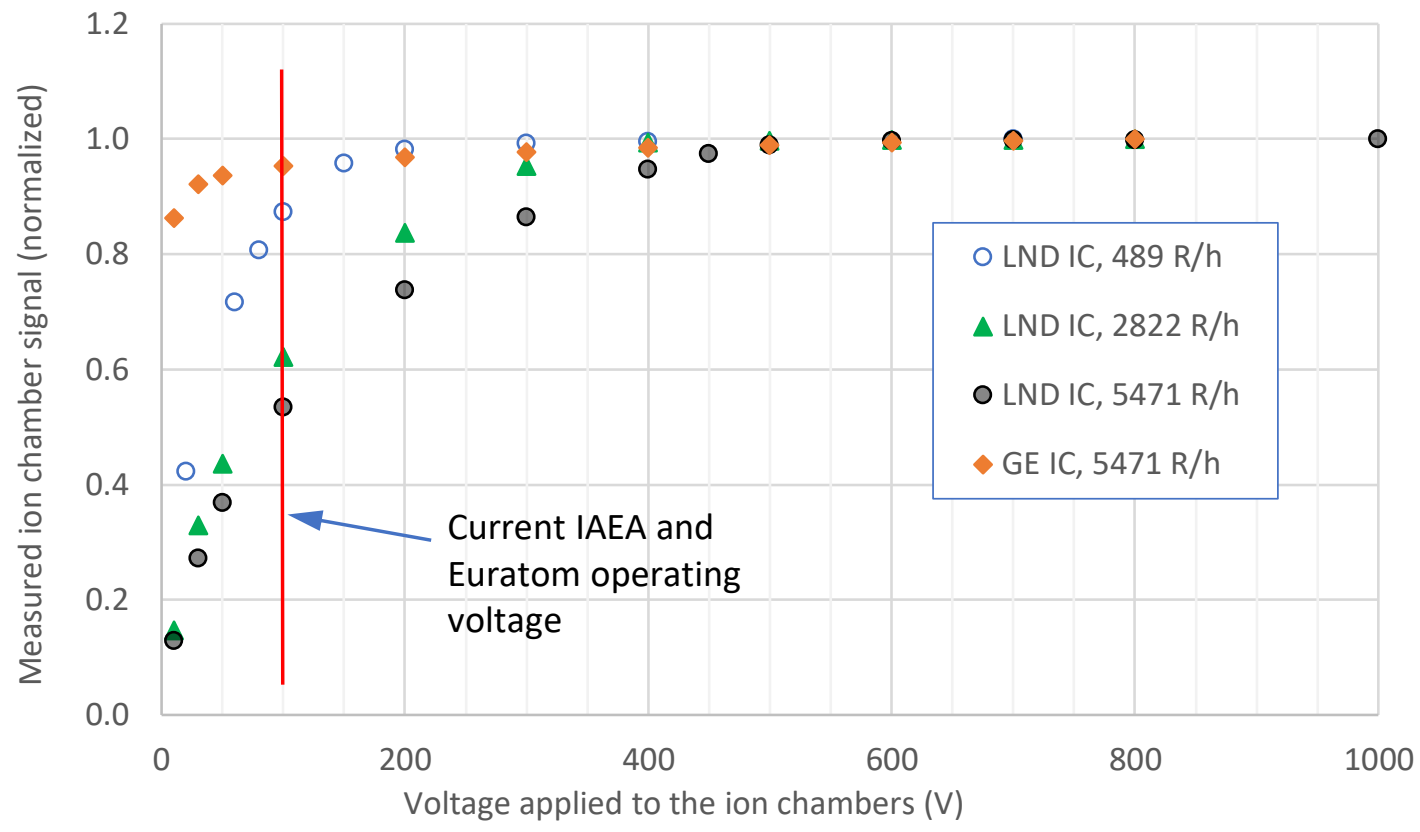

Figure 20. Sensitivity to the operating voltage of the LND 52110 and GE ICs at three different dose rates. LND 52110 ICs are used in the Euratom Fork detectors, and LND 52113 ICs are used in the IAEA Fork detectors. Currently, IAEA and Euratom operate their ICs in the Fork detectors at $100 \mathrm{~V}$.

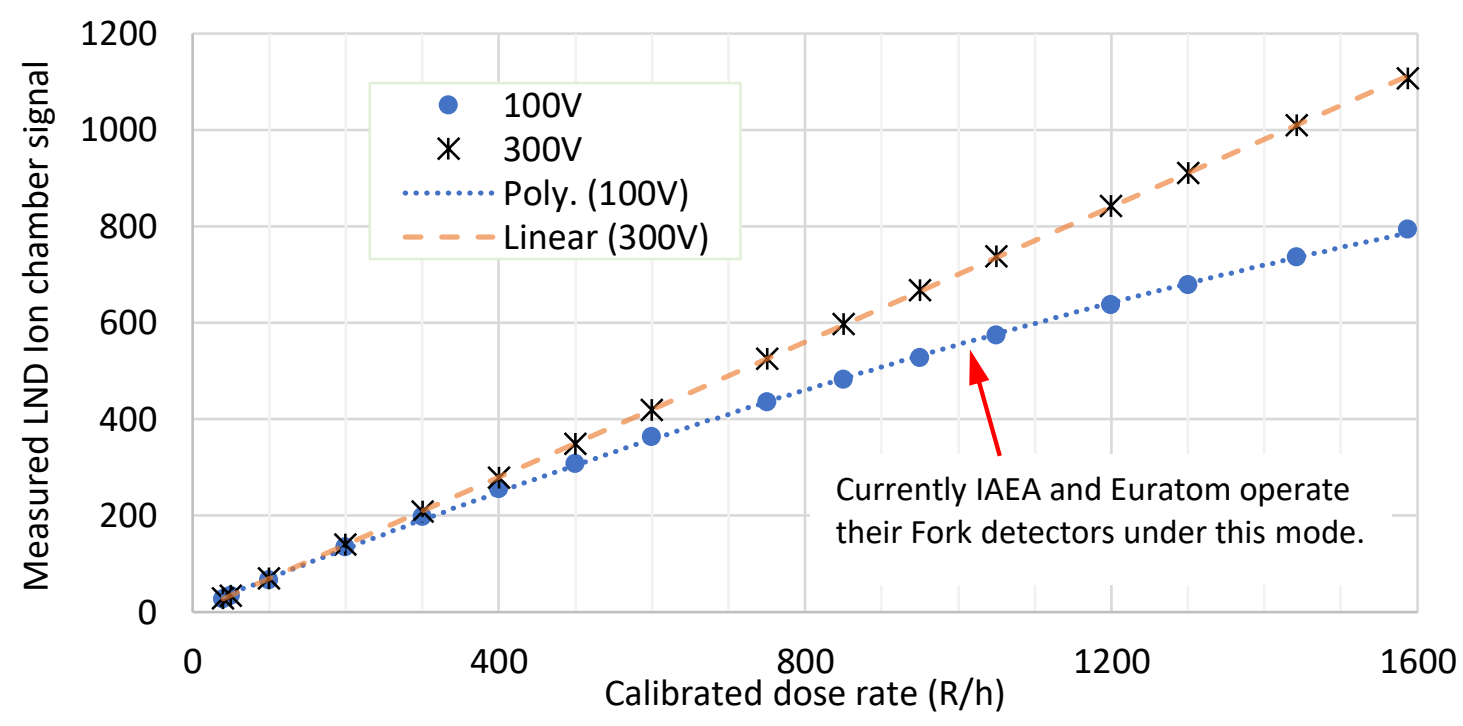

Figure 21. Measured LND 52110 IC signal as a function of dose rates with two different voltages applied to the IC. LND 52110 ICs are used in the Euratom Fork detectors, and LND 52113 ICs are used in the IAEA Fork detectors.

\subsection{HOT CELL MEASUREMENT RESULTS}

As shown in Figure 9, each of the 25 pressurized water reactor and one mixed-oxide spent fuel rod were measured along the length of each fuel rod by using Fork1 and Fork2 with and without the use of the white polyethylene block. Three data acquisition systems (Figure 6) were used. Many data points were collected. A small subset of the results is shown here as examples. Figure 22 shows the normalized 
gamma signal measured by the GE ICs of Fork2 along the length of a spent fuel rod at the ORNL hot cell by using three different data acquisition systems. The upper section of the fuel rod was not measured by the Fork detector because the Fork detector must be set up several feet away from the center of the ADEPT system due to interfering hardware in the hot cell. Although each data acquisition system measures the same electric current from the ICs at a given point, different units were used by each system. The PicoAmmeter reads out Amperes (e.g., Pico Ampere); SMC-2100A outputs "Dose rate" by internally converting the amperage into a dose rate by using the default conversion factor for the LND IC stored in the software; and MiniGrand converts the amperage into some digital units. The conversion factors for SMC-2100A and MiniGrand were minorly adjusted based on the RASCAL measurement results.

Nevertheless, the differences in magnitudes among these three systems can be accounted for by the calibration factors, as long as the system responds to the variations of the IC signals in a similar way. As shown in Figure 22, the data measured by the three systems were in good agreements and followed the trend of fuel burnup along the rod length, indicating that the measurements were properly conducted. Figure 23 shows the neutron count rate measured by the ${ }^{3} \mathrm{He}$ tubes in Fork 2 along the length of a spent fuel rod at the ORNL hot cell by using three different data acquisition systems. Given that the same units (counts per second, or cps) were used, the data were not normalized. Each dataset is in a generally good agreement with others, although the SMC-2100 results were $4 \%$ higher on average than the other two, which is somewhat consistent with the previous observation shown in Figure 15. Similar trends can be observed in the corresponding Fork1 data.

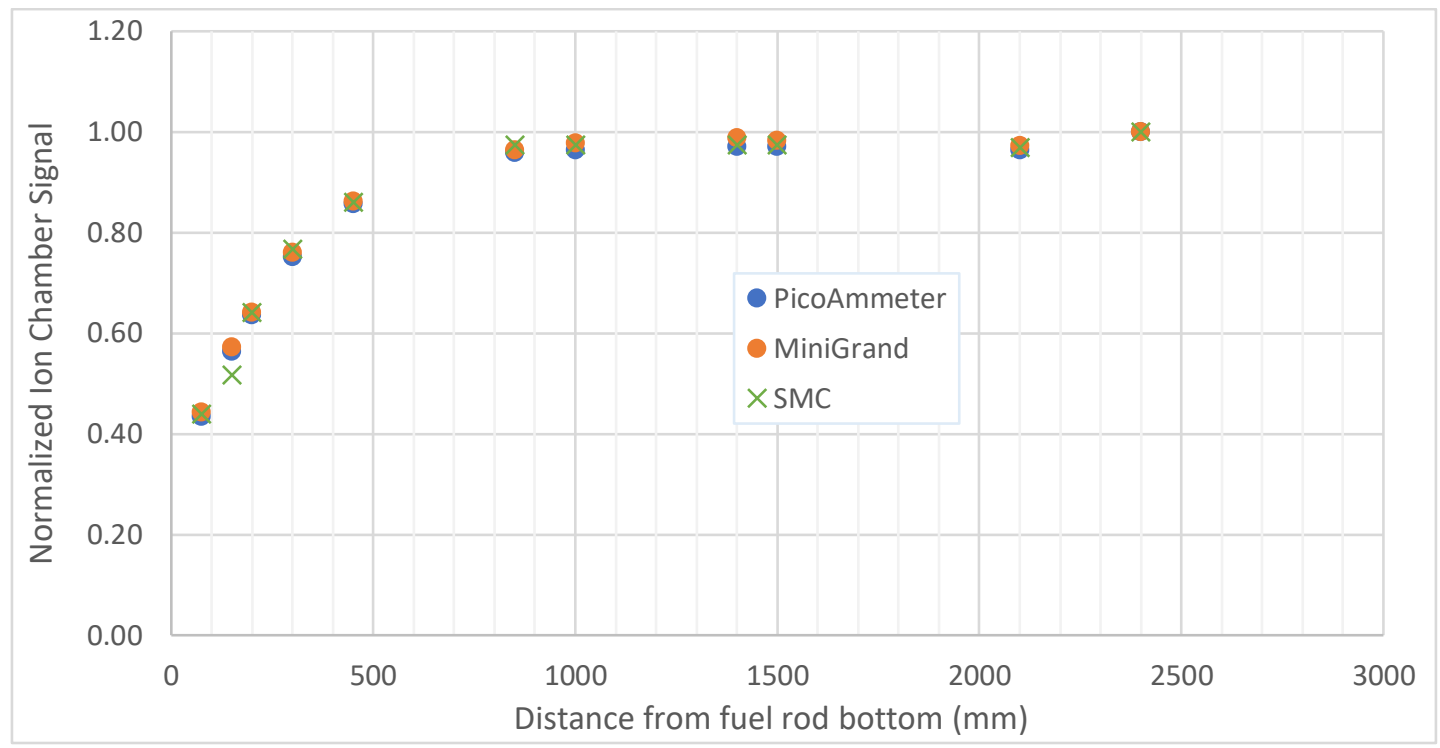

Figure 22. Normalized gamma signal measured by the GE ICs of Fork2 along the length of a spent fuel rod at the ORNL hot cell by using three different data acquisition systems. 


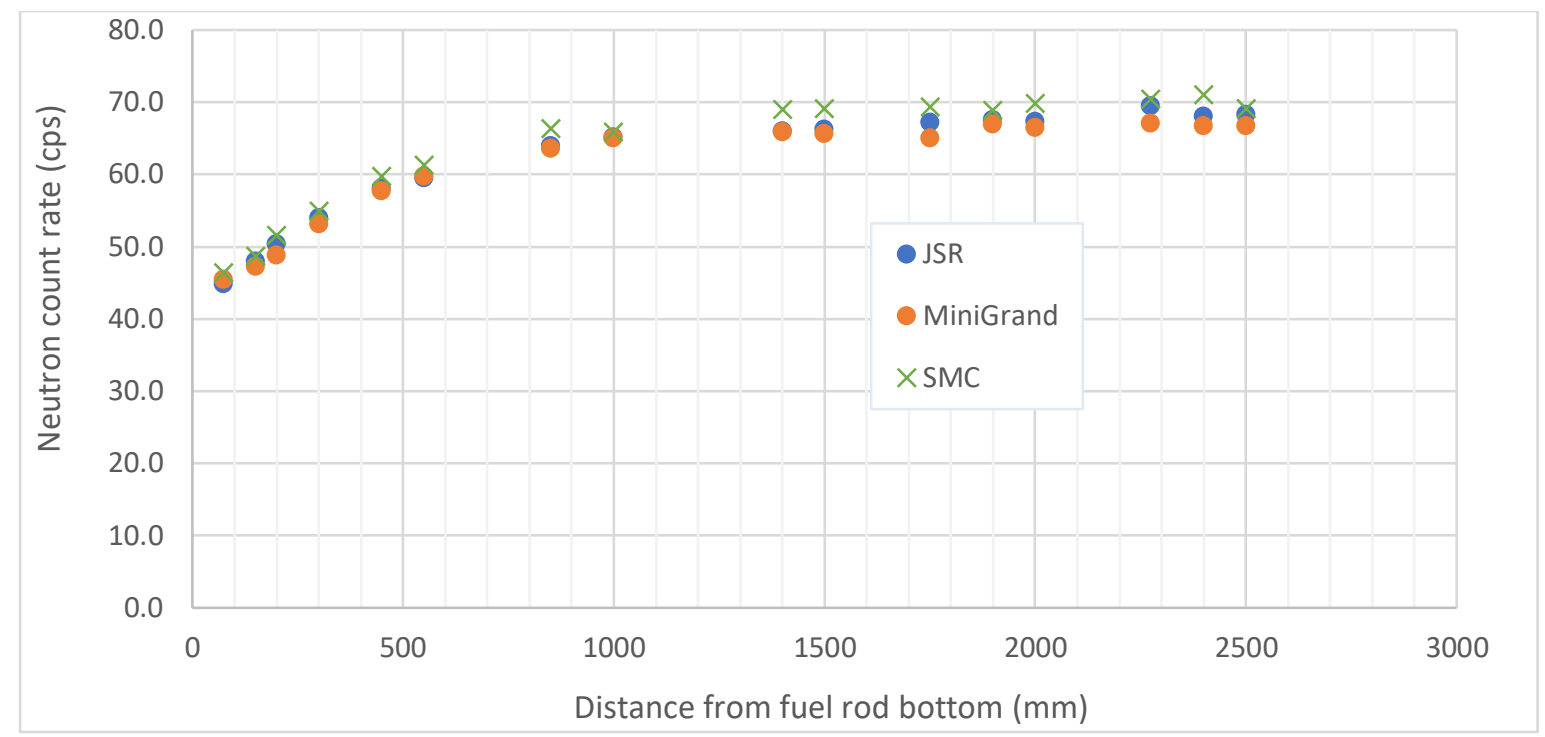

Figure 23. Neutron count rate measured by the ${ }^{3} \mathrm{He}$ tubes in Fork2 along the length of a spent fuel rod at the ORNL hot cell by using three different data acquisition systems.

Figure 24 shows a comparison among normalized Fork count rates and high-purity germanium (HPGe) detector count rates [9] collected from a spent fuel rod (referred to as $\operatorname{Rod} A$ ). The assembly (to which Rod A belonged) average axial burnup profile provided by the operator was also plotted. Two sets of HPGe data are plotted: the ${ }^{137} \mathrm{Cs}$ peak area and total gamma counts. As shown, all count rates follow the general trend of axial burnup profile - low count rates near both ends and flat in the middle. The "dips" shown on the HPGe data correspond to the assembly's spacer grids that depressed the fuel burnups. Such dips did not appear in the Fork count rates. The Fork gamma count rates were closer to the HPGe total counts than the HPGe ${ }^{137} \mathrm{Cs}$ peak because the Fork detector also measures total gamma radiations. The discrepancy between the Fork gamma count rates and the HPGe total counts can be attributed to the fact that the Fork detector was not collimated and hence also measured gammas from other regions of the fuel rod. The plot of neutron count rates exhibited a much steeper slope than the other datasets plotted; this was expected because neutron emissions in spent fuel trend with approximately the fourth power of burnup while gamma emissions are somewhat linear with burnup. Good agreements are shown between the assembly average axial burnup profile and the HPGe total counts, demonstrating that high-quality operator data were provided on these fuel rods. 


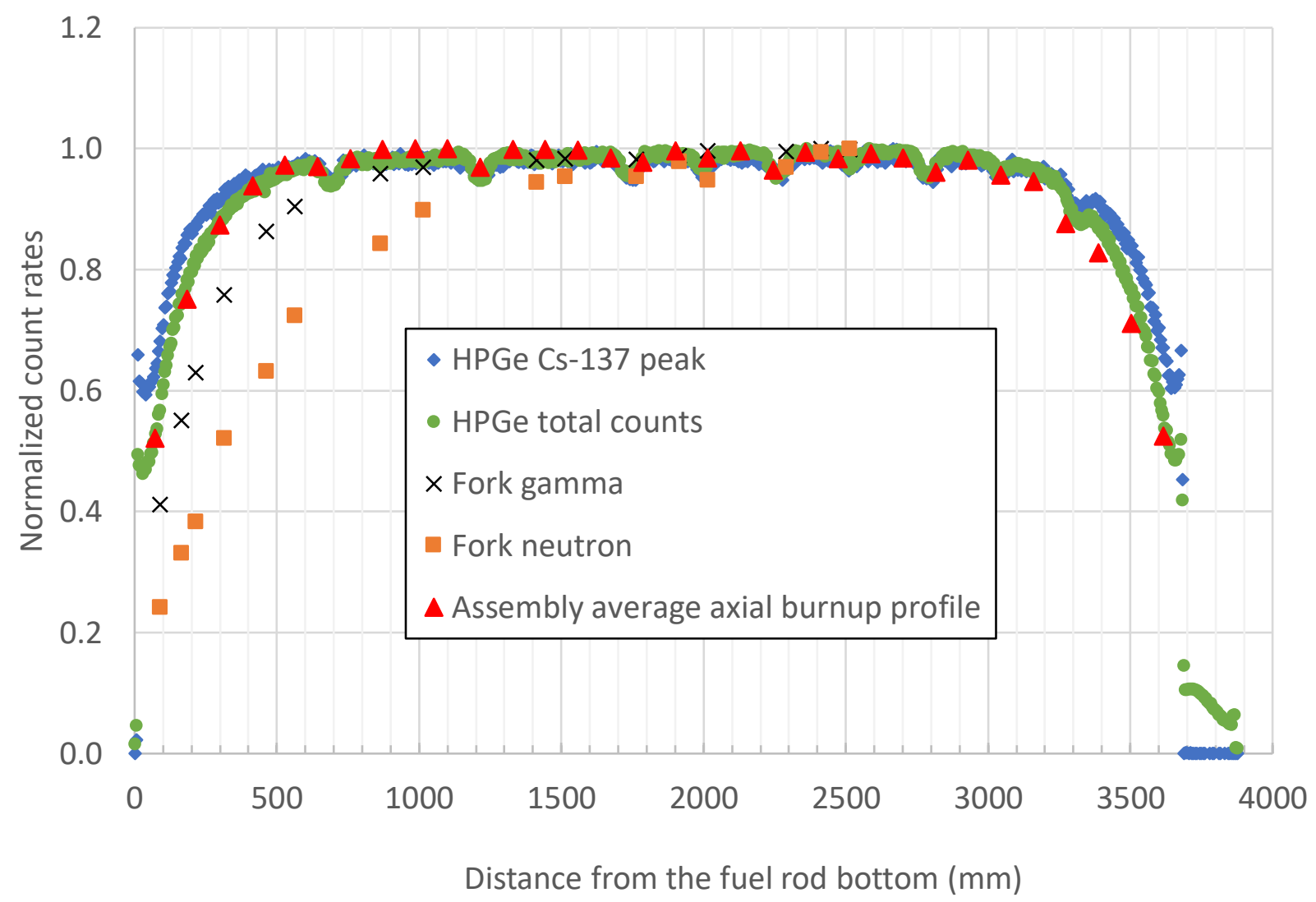

Figure 24. Comparison of count rates collected by the HPGe detector [9] and the Fork detector. The operator data of assembly average axial fuel burnup are also included for reference.

Figure 25 compares the Fork 1 count rates and the corresponding calculated neutron and gamma source intensities based on the operator declarations (e.g., burnup and cooling time) of nine fuel rods. The measured count rates are based on the Fork 1 measurement at the $1,500 \mathrm{~mm}$ position near the axial center of the rod. The measured count rates are expected to be linear with the calculated source intensities for all fuel rods because the measurement geometry was kept the same for all fuel rods. As shown in Figure 25, the measured Fork neutron and gamma count rates trend well with the corresponding calculated source intensities. These results demonstrate that the Fork detector was able to verify the operator declarations of the fuel rods. Figure 26 shows similar results for Fork2. Compared with Figure 25, the Fork2 data were in a closer agreement to the reference line (when measurements were in perfect agreements with calculations) than those of Fork1, indicating that Fork2 has better performance in verifying operator declarations of single fuel rods. 


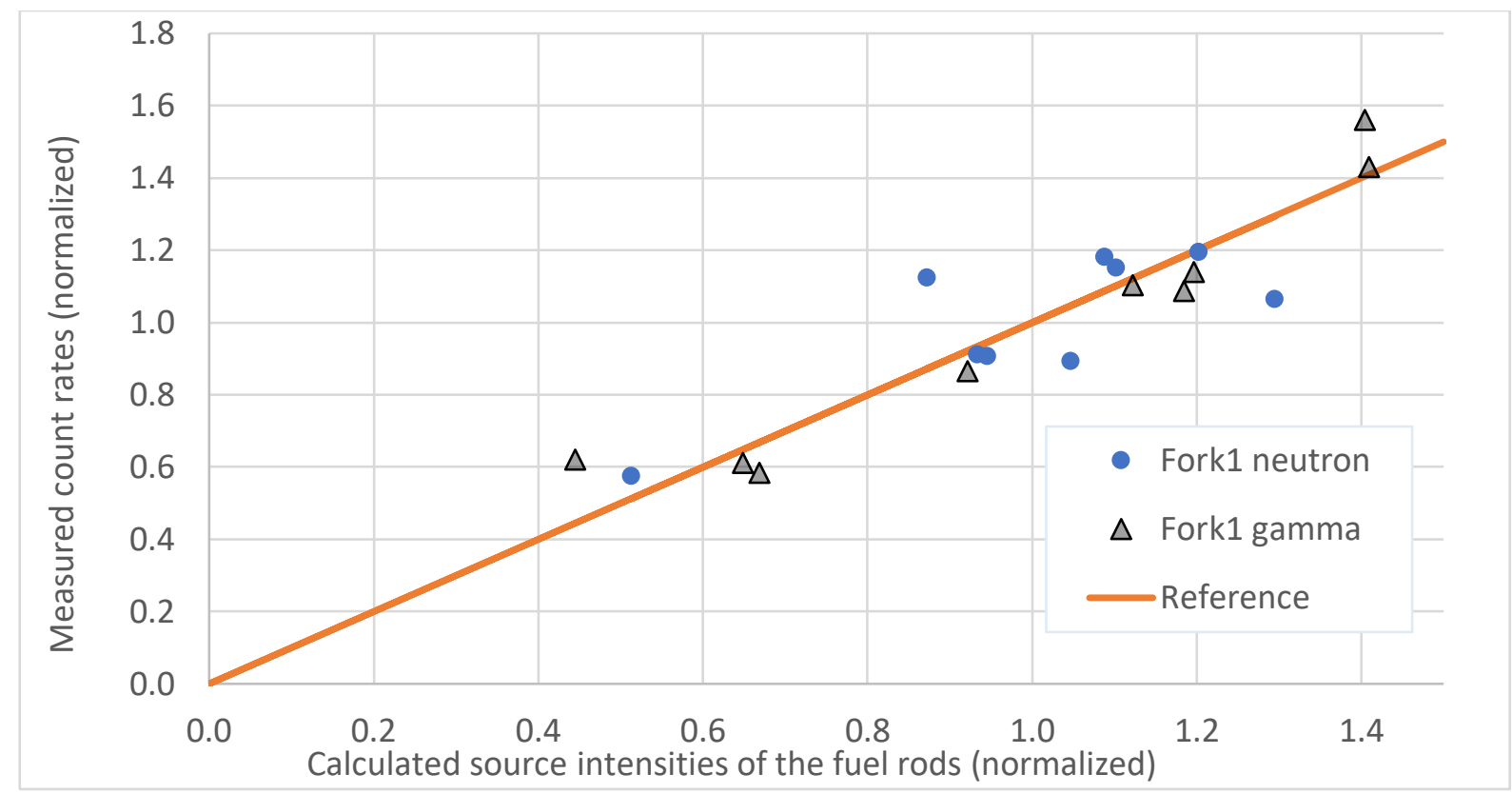

Figure 25. Comparisons between the Fork count rates with the corresponding calculated neutron and gamma source intensities in nine fuel rods.

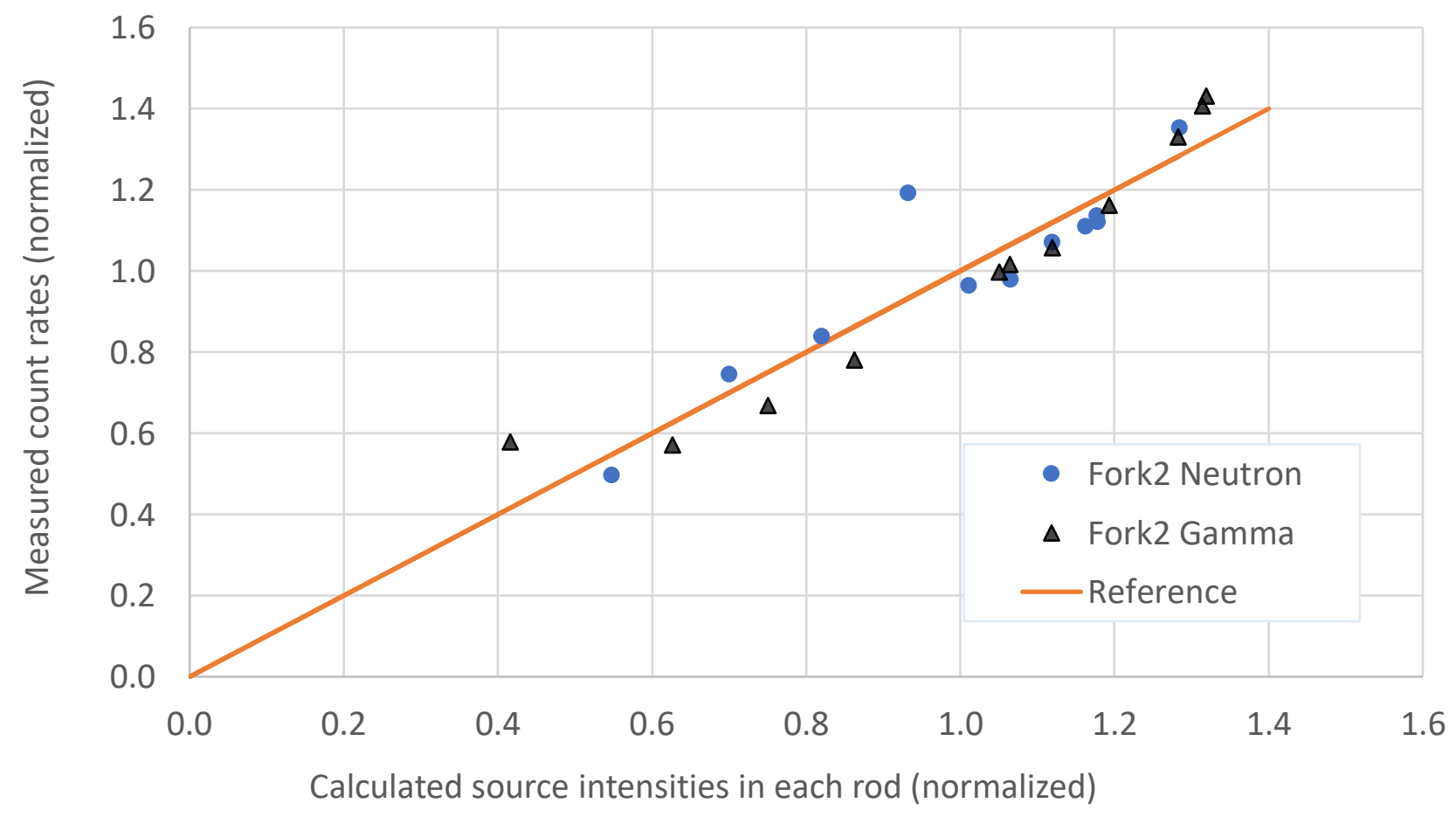

Figure 26. Comparisons between the Fork count rates with the corresponding calculated neutron and gamma source intensities in nine fuel rods.

Figure 27 shows the neutron count rates measured by the ${ }^{3}$ He tubes of Fork 2 as a function of operating voltage under four different gamma dose rates. The gamma dose rates of 400, 1,500, 2,843, and 5,650 R/h were provided by a single fuel rod, the $2 \times 2$, the $3 \times 3$, and the $5 \times 5$ fuel rod array, respectively. As shown, the optimal operating voltages when the neutron count rates were relatively constant with voltages 
for these ${ }^{3} \mathrm{He}$ tubes became smaller at higher gamma dose rates due to the gamma pileups. Thicker shielding for ${ }^{3} \mathrm{He}$ tubes is recommended for measuring full fuel assemblies in the future. Figure 28 shows the neutron count rates measured by the FCs of Fork1 as a function of operating voltage under a gamma dose rate of 2,843 R/h. As shown, the neutron count rates became stable at a voltage beyond $500 \mathrm{~V}$ for these ${ }^{235} \mathrm{U}$ FCs, highlighting FCs reliable performance under high gamma dose rate.

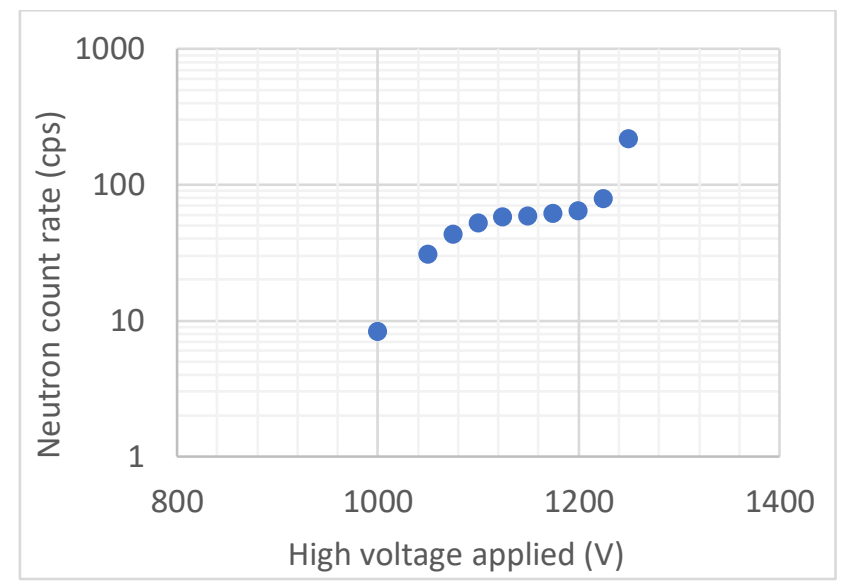

(a) At gamma dose rate of $400 \mathrm{R} / \mathrm{h}$

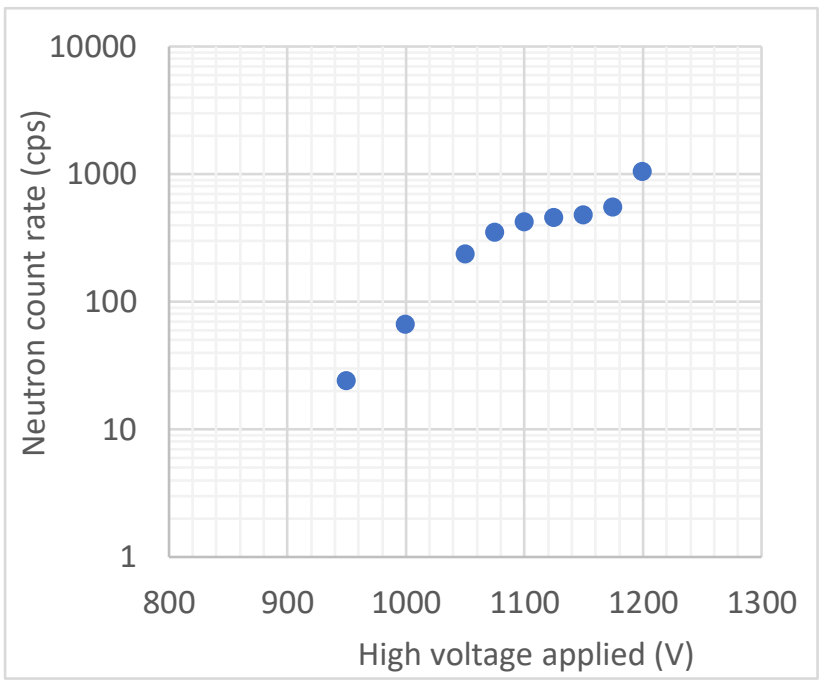

(c) At gamma dose rate of $2,843 \mathrm{R} / \mathrm{h}$

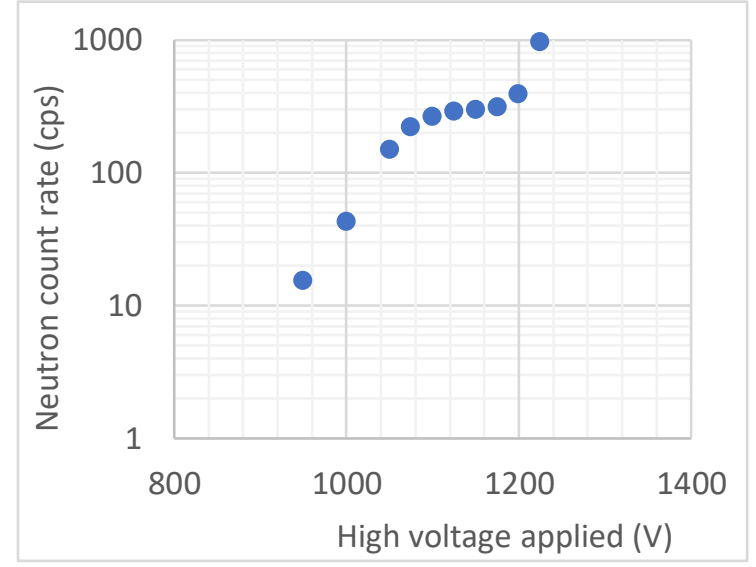

(b) At gamma dose rate of $1,500 \mathrm{R} / \mathrm{h}$

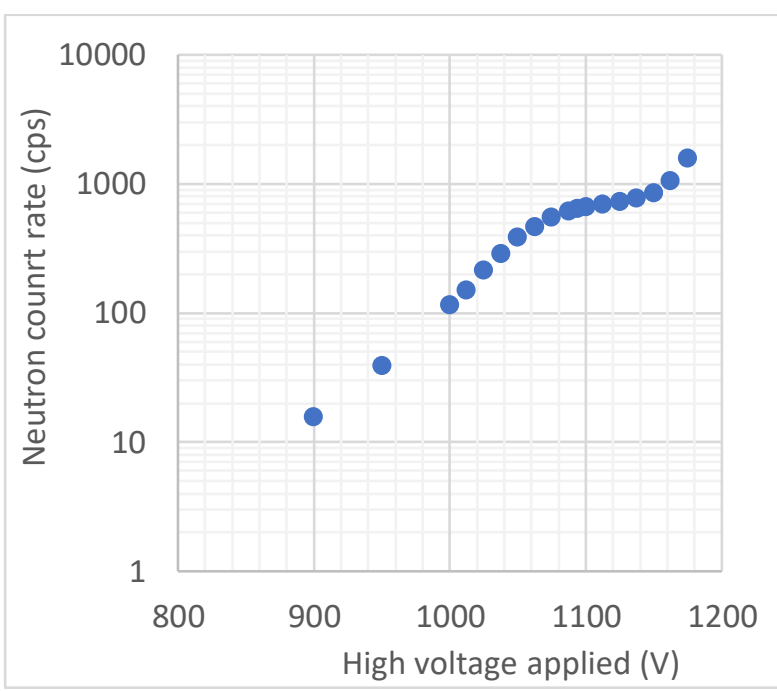

(d) At gamma dose rate of 5,650 R/h

Figure 27. The neutron count rates measured by the ${ }^{3} \mathrm{He}$ tubes of Fork 2 as a function of operating voltage under four different gamma dose rates. 


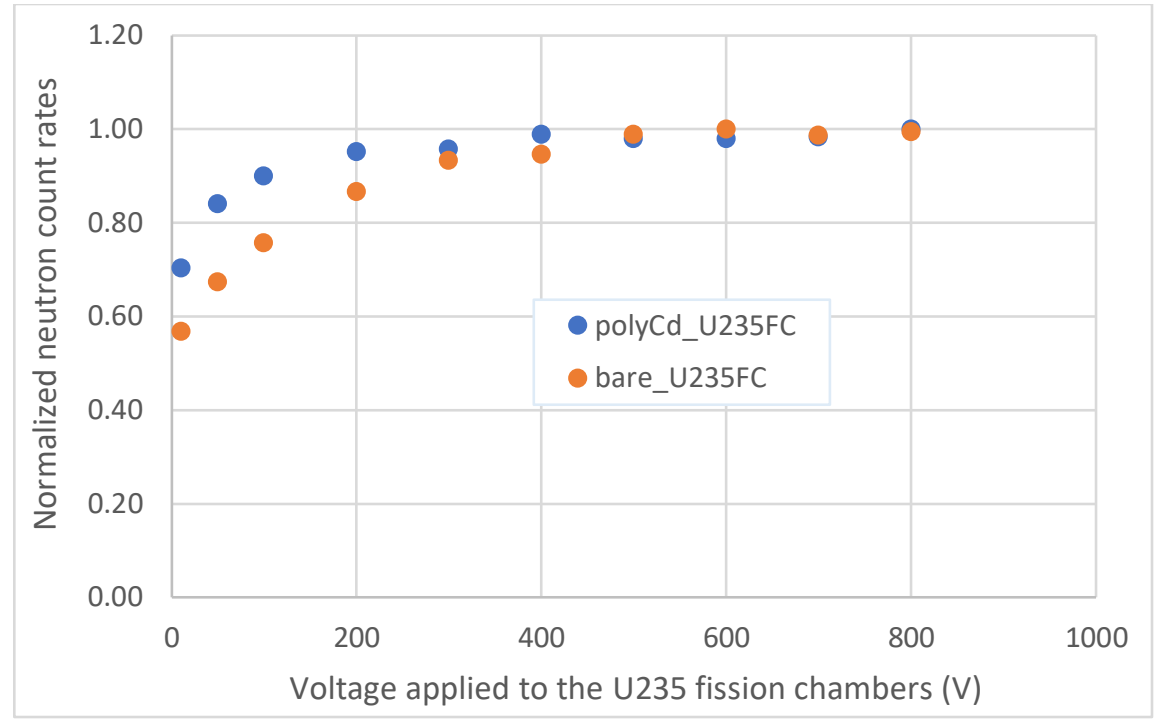

Figure 28. The neutron count rates measured by the FCs of Fork1 as a function of operating voltage under a gamma dose rate of $2,843 \mathrm{R} / \mathrm{h}$.

Figure 29 shows the partial defect test results of Fork1 and Fork2 performed at the ORNL hot cell. "PD4" stands for four rods being replaced by short stainless-steel rods in the $5 \times 5$ array, and "PD8" stands for eight rods replaced; Figure 12 provides more details. The experiment is shown in Figure 11. The "in poly" cases refer to the measurements done directly above the white polyethylene block (Figure 10[a]) with fuel rods in it. The "in air" cases refer to the measurements done between two Al blocks at the middle of the array. To account for the different neutron and gamma emissions from each rod, ORIGEN calculations were performed to calculate the emission rates from each rod, before and after the fuel rods replacement, the calculated reduction of the neutron and gamma emission intensities was also shown in this figure. For the PD4 scenario, $8-14 \%$ and $11-15 \%$ reductions, depending whether the measurement was performed on the poly block or not, were observed in the Fork neutron and gamma count rates, respectively, when compared with the full $5 \times 5$ array. The calculated reductions in neutron/gamma source emissions from the fuel rods due to the removal of the 4 rods were 17 and $20 \%$ for neutron and gamma, respectively. For the scenario of PD8, the reductions were $21-24 \%$ and $32-34 \%$ for neutron and gamma count rates, respectively. The calculated reductions in neutron/gamma source emissions from the fuel rods due to the removal of the 8 rods were 34 and $39 \%$ for neutron and gamma, respectively. The measured reduction values were lower than the calculated values due to self-attenuation effects because the calculations were based on source emission intensities only. The measured reduction values for neutron for several "in poly" cases were lower than the "in air" cases due to the higher attenuations in the polyethylene block. Given that the measurement uncertainties, including counting and detector positioning, were $\sim 2 \%$, these results show that both Fork detectors were capable of detecting these two partial defects in the $5 \times 5$ array in the "in air" and "in poly" scenarios. 


\begin{tabular}{|c|c|c|c|c|c|c|c|c|}
\hline \multirow{3}{*}{$\begin{array}{l}\text { Fork1 } \\
4 / 25=16 \% \\
8 / 25=32 \%\end{array}$} & \multicolumn{4}{|c|}{ Reduction due to PD4 (\%) } & \multicolumn{4}{|c|}{ Reduction due to PD8 (\%) } \\
\hline & \multicolumn{2}{|c|}{ Neutron } & \multicolumn{2}{|c|}{ Gamma } & \multicolumn{2}{|c|}{ Neutron } & \multicolumn{2}{|c|}{ Gamma } \\
\hline & calculated & measured & calculated & measured & calculated & measured & calculated & measured \\
\hline in air & -17 & -14 & -20 & -14 & -34 & -23 & -39 & -32 \\
\hline in poly & -17 & -8 & -20 & -15 & -34 & -21 & -39 & -32 \\
\hline
\end{tabular}

\begin{tabular}{|l|cc|cc|cc|cc|}
\hline \multirow{2}{*}{ Fork2 } & \multicolumn{4}{|c|}{ Reduction due to PD4 (\%) } & \multicolumn{3}{c|}{ Reduction due to PD8 (\%) } \\
\cline { 2 - 9 } & \multicolumn{2}{|c|}{ Neutron } & \multicolumn{2}{c|}{ Gamma } & \multicolumn{2}{c|}{ Neutron } & \multicolumn{2}{c|}{ Gamma } \\
& calculated & measured & calculated & measured & calculated & measured & calculated measured \\
\hline in air & -17 & -12 & -20 & -15 & -34 & -24 & -39 & -34 \\
\hline in poly & -17 & -8 & -20 & -11 & -34 & -21 & -39 & -33 \\
\hline
\end{tabular}

Figure 29. Partial defect test results of Fork1 and Fork2 performed at the ORNL hot cell. "PD4" stands for four rods being replaced by short stainless-steel rods in the $5 \times 5$ array, and "PD8" stands for eight rods replaced.

Figure 12 provides more details.

\section{SUMMARY AND CONCLUSIONS}

International safeguards authorities are facing increased technical challenges related to spent nuclear fuel due to the increased fuel transfer activities around the world, including dry storage loading and fuel encapsulation for the near-future repository disposals. The in-air spent fuel safeguards measurements planned in the Finnish spent fuel encapsulation plant for the geological repository present unique challenges. The Fork detector will likely remain one of the primary instruments for meeting these challenges. The spent fuel rods made available by the DOE NE project provided a unique and desirable opportunity to test the Fork detector's performance for in-air measurements and collect data to validate the ORIGEN Module. Much work was done under this project. The results show that: (1) the Fork detectors performed well in air, (2) the root cause of nonlinear gamma response in the standard Fork detectors was identified to be the insufficient operating voltage of the ICs under high dose rates, (3) the Fork count rates are consistent with other datasets, (4) the Fork detector can verify operator declarations, and (5) the Fork detector can detect partial defects. This report serves as an archive of this work, which lays a foundation for a future publication when resources become available. The large quantity of experimental data on spent fuel radiation measurement collected in this work can be a valuable database for future work for safeguards and other spent fuel related research areas. 


\section{REFERENCES}

[1] J. Scaglione, R. Montgomery and B. Bevard, "Post Irradiation Examination Plan for High Burnup Demonstration Project Sister Rods," ORNL/SR-2016/111, Oak Ridge, 2017.

[2] IAEA, "Safeguards Techniques and Equipment: 2011 Edition," IAEA, http://wwwpub.iaea.org/MTCD/Publications/PDF/nvs1_web.pdf, Vienna, 2011.

[3] I. Gauld, J. Hu, P. D. Baere and e. al., "In-Field Performance Testing of the Fork Detector for Quantitative Spent Fuel Verification," in ESARDA, ISBN 978-92-79-49495-6, Manchester, UK, 2015.

[4] LND inc, "52110 Gamma Ionization Chamber," [Online]. Available: https://www.Indinc.com/products/ionization-chambers/52110/.

[5] LND inc, "52113 Gamma Ionization Chamber," [Online]. Available: https://www.Indinc.com/products/ionization-chambers/52113/.

[6] ANTECH, [Online]. Available: http://www.antech-inc.com/.

[7] Y. G. Lee, "Development of "Fission Chamber Free" Fork Detector for Safeguards Measures on LWR Spent Fuel Assemblies," in IAEA Symposium, Vienna, 2014.

[8] S. Yoon, "Evaluation of the SCALE/ORIGEN/ORELLA Software Package for Analysis of FDET Measurement Data," IAEA, report SG-RP-14042, 2016.

[9] S. Smith, A. Nicholson, S. Croft and G. Nutter, "Measurement of Pressurized Water Reactor Spent Nuclear Fuel Rods by High-Resolution Gamma Spectroscopy for Burnup Code Verification,"

ORNL/SPR-2017/381, Oak Ridge, 2017. 
